\title{
Discerning dominant temporal patterns of bio-optical properties in the northwestern Mediterranean Sea (BOUSSOLE site)
}

\author{
Bellacicco M. ${ }^{1,}{ }^{*}$, Vellucci V. ${ }^{2}$, D'Ortenzio F. ${ }^{1}$, Antoine D. ${ }^{1,3}$
}

1 Sorbonne Univ, CNRS, LOV, F-06230 Villefranche Sur Mer, France.

2 Sorbonne Univ, CNRS, Inst La Mer Villefranche, IMEV, F-06230 Villefranche Sur Mer, France.

${ }^{3}$ Curtin Univ, Sch Earth \& Planetary Sci, Remote Sensing \& Satellite Res Grp, Perth, WA 6845,

Australia.

* Corresponding author : M. Bellacicco, email address : Marco.Bellacicco@obs-vlfr.fr

\begin{abstract}
:
A wavelet analysis has been applied, for the first time, to 3-year high-frequency field observations of bio-optical properties (i.e. chlorophyll-fluorescence, beam attenuation and backscattering coefficients) in the northwestern Mediterranean Sea (BOUSSOLE site), in order to identify their dominant temporal patterns and evolution. A cross-wavelet and coherence analysis has also been applied to paired biooptical coefficients time-series at the BOUSSOLE site, which allows identifying the temporal relationship between the cycles of the bio-optical properties. Annual, six- and four-month, intra-seasonal (i.e., midand short-terms) cycles are identified from the time-series analysis. The periodicities of chlorophyllfluorescence, beam attenuation and particulate back-scattering coefficients correlate well at different temporal scales and specific seasons. At annual, six- and four-month scales, different bio-optical properties follow rather similar patterns, likely driven by physical forcing. Intra-seasonal variability consists in both mid- and short-term variations. The former dominates during the winter and are related to episodic bloom events, while the latter variations (i.e., diel) prevail during summer, in a stratified water column.
\end{abstract}

\section{Highlights}

- The Chl-Fluo variability has driven mostly by annual cycle. The $c_{p}$ and bbp coefficients have driven mostly by 6-months cycle. During winter, mid-term cycles (greater than 10 days) dominate the intraseasonal signal for all parameters. During summer, diel cycle has a strong impact on the intraseasonal variability for all parameters.

Keywords : Phenology, Bio-optical properties, Time-series analysis, Wavelet analysis 
Phenology is the study of the timing of periodic life events (Morren, 1849a; Winder et al., 2010). It was first investigated on terrestrial plants, which are sensitive to climate variability (Cleland et al., 2007; Winder et al., 2010). Phenology of marine ecosystems has been studied for a few decades, especially by use of bio-optical proxies that are accessible through satellite ocean color remote sensing. In the ocean, phytoplankton are considered as a sentinel of changes in the ecosystems, because they respond rapidly to environmental perturbations (Bode et al., 2015). In such a context, several studies on phytoplankton phenology (i.e. seasonal and annual cycles) have been conducted in marine ecosystems, from inland to open ocean waters, using chlorophyll-a data (Behrenfeld et al. 2010, 2016; Winder et al. 2010; Carey et al. 2016; Mignot et al., 2018). Other cycles (e.g. lowest temporal cycles) are less well-known.

In the ocean, changes in nutrients and light conditions have an impact on the phytoplankton standing stock and on the intracellular chlorophyll concentration (Chl), which is widely used as a proxy for phytoplankton biomass (Volpe et al., 2012; Siegel et al., 2013). In the Mediterranean Sea, under high nutrients and low light, phytoplankton growth rate shows the maximum concentration values. When light intensity increases, there is no longer a need for the cells to produce and sustain large amounts of the energetically expensive chlorophyll pigment. Under these conditions, phytoplankton exploit the nutrients still present in the upper layer. This, together with the light conditions provided by the increased stratification, allows phytoplankton to grow, despite phytoplankton chlorophyll concentration decreases. The condition of the strong increase in light determines the decline of phytoplankton pigment demand, while low nutrient concentrations limit phytoplankton population growth and division rates. Under low nutrients (generally the period of highest stratification of water column) and high light conditions, phytoplankton shows the minima of abundance. When light starts to decrease and mixing occurs again, phytoplankton assign the energy from the newly available nutrients into the production of chlorophyll, however, limiting their growth rate (Lavigne et al., 2013; Bellacicco et al. 2016; Barbieux et al., 2018).

In temperate seas like the Mediterranean Sea, a major feature of the annual cycle is the spring bloom, as it occurs, for instance, in the Gulf of Lion (D'Ortenzio et al., 2014; Mayot et al., 2017). This bloom typically persists for a few weeks to months. The variability of phytoplankton annual and seasonal patterns has thus been well studied (Behrenfeld et al. 2010; Volpe et al., 2012; Lavigne et al., 2013, Mignot et al., 2014), while no systematic analyses at shorter time scales have been conducted to identify the characteristic periods of biomass variability and recurrence along years at these scales. Winder et al. (2010) defined the mid- and low-term phytoplankton fluctuations as irregular blooms that are often responses to short-term weather events which affect sea temperature and vertical mixing dynamics. However, several works have shown that Chl can be complemented with other parameters to describe the ocean ecosystem complexity and phytoplankton dynamics (Behrenfeld et al. 2005, 2006; Ji et al., 2010). These works demonstrated that the physiological processes affect the carbon to chlorophyll ratio (Halsey and Jones, 2015), especially during intermediate periods of light and nutrients variations, as it occurs in the Mediterranean Sea (Bellacicco et al., 2016). Furthermore, biological processes such as phytoplankton photosynthesis and cellular growth and division can be associated with short-term temporal variations like the daily light-dark cycle (Neveux et al., 2003; Poulin et al., 2018). Diel variability is often not taken into account in the current ocean colour algorithms, but many laboratory experiments and studies have demonstrated that, in seawater, there is a diurnal variation 
of optical properties, from midday to night, that have implications on biomass measurements (Poulin et al., 2018). Thus, the use of other proxies, such as optical coefficients, may be helpful to investigate the different temporal scales of phytoplankton avoiding to take into account the effect of physiological processes on $\mathrm{Chl}$ content. In such a context, bio-optical relationships have been widely established between inherent optical properties (IOPs) and the main biogeochemical parameters, such as the Chl concentration or fluorescence (Huot et al., 2007, 2008; Dall'Olmo et al., 2009, 2012; Brewin et al., 2012; Antoine et al. 2011; Martinez-Vicente et al., 2013; Barbieux et al., 2018; Bellacicco et al., 2018).

One of the most studied IOPs is the particulate beam attenuation coefficient, $c_{p}$, used as a proxy for particle concentration and sensitive to a size range that includes phytoplankton cells (Claustre et al., 1999; Behrenfeld and Boss, 2003). $\mathrm{c}_{\mathrm{p}}$ is the sum of particulate scattering and absorption coefficients. Its diel variation is primarily due to planktonic adaptation to the daily light cycle, the dynamics of the upper mixed layer and the variations of particles mass (Siegel et al., 1989; Walsh et al., 1995; Stramski and Reynolds, 1993; Durand and Olson, 1998). The interpretation of diel variability of $c_{p}$ is difficult because it depends on several factors, such as: i) phytoplankton concentration and composition, ii) physiological status (i.e. photoacclimation), and iii) concentrations of detritus and small heterotrophs (e.g. heterotrophic bacteria). The compound effect of variations of these factors on $c_{p}$ remains poorly known (Kheireddine et al., 2014). Recently, Gernez et al. (2011) and Kheireddine et al. (2014) have shown that the amplitude and phasing of $\mathrm{c}_{\mathrm{p}}$ diel cycles vary seasonally, which may result from seasonal changes in nutrient concentrations, phytoplankton abundance, size distribution, and composition. Unfortunately, $\mathrm{c}_{\mathrm{p}}$ is not directly derivable from satellite observations, thus limiting its applications. The IOP that is directly proportional to the ocean reflectance and can be retrieved from space is the particulate backscattering coefficient, $b_{b p}$ (Lee et al., 2002). Similarly to $c_{p}, b_{b p}$ is related to particle concentration to the first order, whereas it also contains information on the particle size distribution, refractive index, shape and structure of particles (Twardowski et al., 2001, Neukermans et al., 2012, Slade and Boss, 2015). $\mathrm{b}_{\mathrm{bp}}$ is more influenced than $\mathrm{c}_{\mathrm{p}}$ by submicron non-algal particles (Morel and Ahn, 1991; Stramski and Kiefer, 1991, Stramski et al., 2004), yet their magnitude both covary with phytoplankton concentration, allowing relationships between $\mathrm{b}_{\mathrm{bp}}$ and $\mathrm{Chl}$ to be observed (Bellacicco et al., 2016, 2018; Barbieux et al., 2018). Organelli et al., (2018) suggest that most of $b_{\mathrm{bp}}$ signal is due to particles with equivalent diameters between 1 and $10 \mu \mathrm{m}$, and thus may be significantly influenced by phytoplankton. Several studies have shown good relationships between both the optical coefficients and phytoplankton in terms of Chl, carbon or fluorescence, on both global and regional scales (Behrenfeld and Boss, 2003; Behrenfeld et al., 2005; Dall'Olmo et al., 2009, 2012; Antoine et al., 2011; Brewin et al., 2012; Martinez-Vicente et al., 2013; Barbieux et al., 2018; Bellacicco et al., 2018). The complexity of temporal relationships between $\mathrm{c}_{\mathrm{p}}$, $\mathrm{b}_{\mathrm{bp}}$, and phytoplankton biomass proxies should be, thus, studied and observed at a range from diel to annual cycles.

The objectives of this study are to determine the intra-annual dominant temporal patterns (from the lowest up to annual cycles) of the above-mentioned bio-optical parameters, the changes of these cycles over time, the characteristics and recurrence strength at those periods and to define the temporal relationship between the cycles of the bio-optical properties. To this aim a Wavelet Analysis (WA) was applied, for the first time, to a 3-year time-series (2011-2013) of surface Chlfluorescence, $b_{b p}$ and $c_{p}$ at the BOUSSOLE site in the northwestern (NW) Mediterranean Sea 
(Antoine et al., 2006; Figure 1), enabling the detection of all the intra-annual dominant temporal patterns.

\section{Area of study, data and methods}

\subsection{BOUSSOLE site}

133

The BOUSSOLE (BOUee pour l'acquiSition d'une Série Optique a Long termE) project started in 1999, and its activities are developed on a site located in the northwestern Mediterranean Sea, at about 32 nautical miles from the French coast (Figure 1). Essential information about the site characteristics, the measurement platform, and the instrumentation are also provided in Antoine et al. $(2006,2008 \mathrm{a}, \mathrm{b})$. The site is protected from coastal inputs by the Ligurian Current, which flows along the coast toward the southwest (Millot, 1999). The physical conditions of the area show strong seasonality (D'Ortenzio et al., 2014), with deep $(\sim 400 \mathrm{~m})$ mixed layers in winter, and a marked stratification in summer ( $20 \mathrm{~m}$; Antoine et al., 2011; Mayot et al., 2017). Hydrodynamics drive seasonal changes in phytoplankton abundance, which shows a typical mid-latitude temporal pattern. Oligotrophic conditions prevail in summer where $\mathrm{Chl}$ is about $0.1 \mathrm{mg} \mathrm{m}^{-3}$ (minima $\sim 0.05$ $\mathrm{mg} \mathrm{m}^{-3}$ ), and concentrations increase up to $3-5 \mathrm{mg} \mathrm{m}^{-3}$ during the spring bloom, and stay between $0.1-0.3 \mathrm{mg} \mathrm{m}^{-3}$ the rest of the year (Gernez et al., 2011, Kheireddine et al., 2014). There is, accordingly, a large range of optical properties (Antoine et al., 2006; Gernez et al., 2011), as observed over the entire northwestern Mediterranean Sea (Bosc et al., 2004).

A moored buoy has been permanently deployed at the BOUSSOLE site since September 2003 and operates in a quasi-continuous mode, with data acquisition for one minute every 15 min both night and day. Adequate measures have to be taken to minimize or eliminate bio-fouling, which is unavoidable with moored instrument. All instruments installed on the BOUSSOLE buoy are cleaned by divers about every 2 weeks.

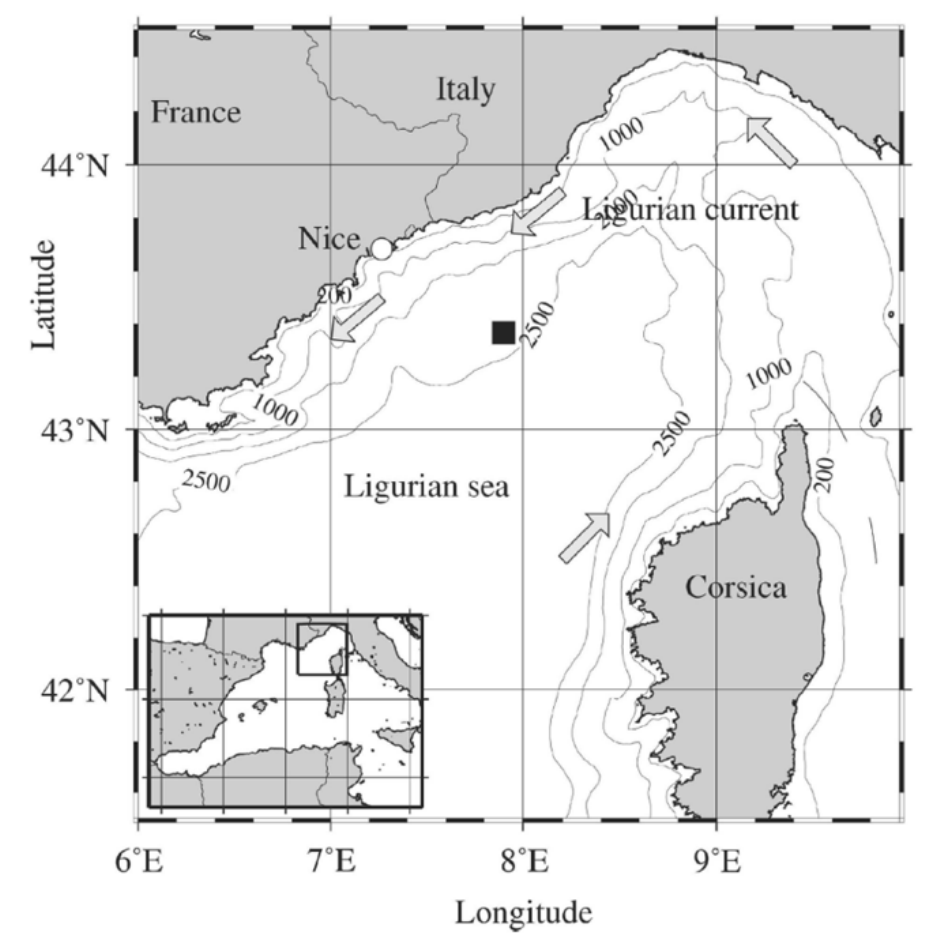


Figure 1: The area of the north-western Mediterranean Sea showing the main current branches (grey arrows), and the location of the BOUSSOLE site in the Ligurian Sea (black square) (Antoine et al., 2011).

\section{6}

157

158

159

160

161

162

163

164

165

166

167

168

169

170

171

172

173

174

175

176

177

178

179

180

181

182

183

184

185

186

187

188

189

\subsection{Optical measurements}

The volume scattering function at $140^{\circ}, \beta(140)$, is measured using in alternation two HOBI Labs Hydroscat-4 backscattering meters installed at the lower measurements depth of the buoy (ca. $9 \mathrm{~m})$. Instruments are calibrated before deployments (which last about 6 to 12 months) and are equipped with filters at $442,488,550$, and $620 \mathrm{~nm}$, here only the green band is used. The instruments operate at $1 \mathrm{~Hz}$, so that about 60 measurements are recorded during 1 minute, from which the median is taken as representative for $\beta(140)$. Dark current measurements are performed on site with a neoprene cap covering the instrument windows, average dark readings are subtracted to the timeseries for each deployment. The $\beta(140)$ values are also corrected for attenuation along the measurement path (the $\sigma(\lambda)$ correction of Maffione and Dana, 1997) using $\mathrm{c}_{\mathrm{p}}$ (see below) and the total absorption coefficient derived from inversion of the diffuse attenuation coefficient for downward irradiance $\left(\mathrm{K}_{\mathrm{d}}\right)$ and the irradiance reflectance $(\mathrm{R}) . \mathrm{K}_{\mathrm{d}}$ and $\mathrm{R}$ are retrieved from parallel measurements performed with a set of Satlantic OCR-200 series radiometers. $b_{b p}$ is derived from the corrected $\beta(140)$ as follows (Maffione and Dana 1997; Boss and Pegau, 2001):

$$
\mathrm{b}_{\mathrm{bp}}(550)=2 \pi \chi \mathrm{p}\left(\beta(140,550)-\beta_{\mathrm{w}}(140,550)\right) \quad\left(\mathrm{m}^{-1}\right)
$$

where $\chi_{\mathrm{p}}=1.13$ (D. R. Dana and R. A. Maffione, unpublished manuscript, 2014) and $\beta_{w}(140)$, the pure seawater scattering at $140^{\circ}$, is computed following Zhang et al., (2009); Zhang and Hu (2009) using the temperature and salinity measured at the same depth with a Sea-Bird Scientific SBE-37SI CTD sensor.

The particulate transmittance $\left(\operatorname{Tr}_{\mathrm{p}}, \%\right)$ at $650 \mathrm{~nm}$ is measured at 4 and $9 \mathrm{~m}$ with $25 \mathrm{~cm}$ path length WETLabs C-Star transmissometers (acceptance angle is $1.2^{\circ}$ ). Instruments are factory calibrated with deionized, ultra-filtered, UV-screened water. The corresponding particulate beam attenuation coefficient, $c_{p}$, is then calculated as:

$\mathrm{c}_{\mathrm{p}}(650)=-\frac{1}{0.25} \ln \left(\frac{\operatorname{Tr}_{p}(650)}{100}\right) \quad\left(\mathrm{m}^{-1}\right)$

This assumes that absorption by colored dissolved organic matter (CDOM) is negligible at $650 \mathrm{~nm}$ (Bricaud et al., 1981).

Chlorophyll-a fluorescence (Chl-Fluo) is measured in RFU with an ECOFLNTUs WET Labs (now Sea-Bird Scientific) fluorimeter $(470 \quad \mathrm{~nm} \quad$ EX/695 $\mathrm{nm} \quad \mathrm{EM}$; see https://www.seabird.com/combination-sensors/eco-flntu/family?productCategoryId=54758054352) at $4 \mathrm{~m}$ and $9 \mathrm{~m}$ depth.

In this study, we selected $b_{b p}, c_{p}$ and $\mathrm{Chl}$ Fluo at the depth of $9 \mathrm{~m}$ in order to compare them together. Here, $b_{b p}$ is referred to $b_{b p}$ at $\left.550 \mathrm{~nm}^{-1}\right), \mathrm{c}_{\mathrm{p}}$ to $\mathrm{c}_{\mathrm{p}}$ at $650 \mathrm{~nm}\left(\mathrm{~m}^{-1}\right)$.

\subsection{Multi-Channel Spectral Analysis (M-SSA)}

For each parameter, the period from to 2011 to 2013 was used for a total of 105216 measurements after quality control (Figure 2$)$. It consists in removing outliers using three standard deviations $( \pm \sigma)$ confidence limit. 
194 An important prerequisite for applying WA is that the time-series has to be continuous at the 195 minimum considered frequency. Missing data, including those not passing quality control, 196 represented $19.57 \%, 13.40 \%$ and $22.38 \%$ of Chl-Fluo, $b_{b p}$ and $c_{p}$ time-series, respectively. Gaps 197 were filled using a Multi-Channel Singular Spectral Analysis (M-SSA) technique which is a non198 parametric spectral estimation method relying on data only (Ghil et al., 2002; Kondrashov et al. 199 2006, 2010). This technique is not based on a priori parametrized family of probability distribution. 200 The method uses temporal correlation to fill in the missing data and represents a generalization of 201 the Beckers et al., (2003) spatial empirical orthogonal functions-(EOFs) based reconstruction. 202 Kondrashov and Ghil (2006) demonstrated that an increased number of gaps yields the same effect 203 as an increase of the noise in the measurements. Two different inputs are required to apply M-SSA 204 for field reconstruction: window-length $(W)$ and components $(M)$. Both depend on the 205 characteristics of the time-series, and need to be accurately defined to avoid any bias in the 206 reconstructed fields. The $W$ represents the length of the sliding window (expressed in number of 207 observation) used in the M-SSA in order to identify the leading components of the time-series (Ghil 208 et al., 2002; Kondrashov et al. 2006, 2010). Diversely, $M$ is the number of eigen-functions used for 209 signal reconstruction. Here, we applied the M-SSA to the three time-series using specific $W$ 210 ( $W=5000$ ) and $M$ components (i.e., $M=1$ up to 20) following the recommendations listed in Ghil et 211 al., (2002) and Kondrashov et al. (2005, 2006, 2010). These settings are compatible with the 212 properties of the time-series hereby analyzed, taking into account long, mid- and short-term 213 variations. Figure 2 ( $a, b, c)$ shows the time series of each parameter with missing data 214 reconstructed after application of M-SSA technique. Figure $2 \mathrm{~d}$ is the M-SSA spectrum of filled 215 time-series with $W=5000$. The optimum number $M=20$ corresponds to the number of modes that 216 explain more than $95 \%$ of the variance the M-SSA spectrum. 

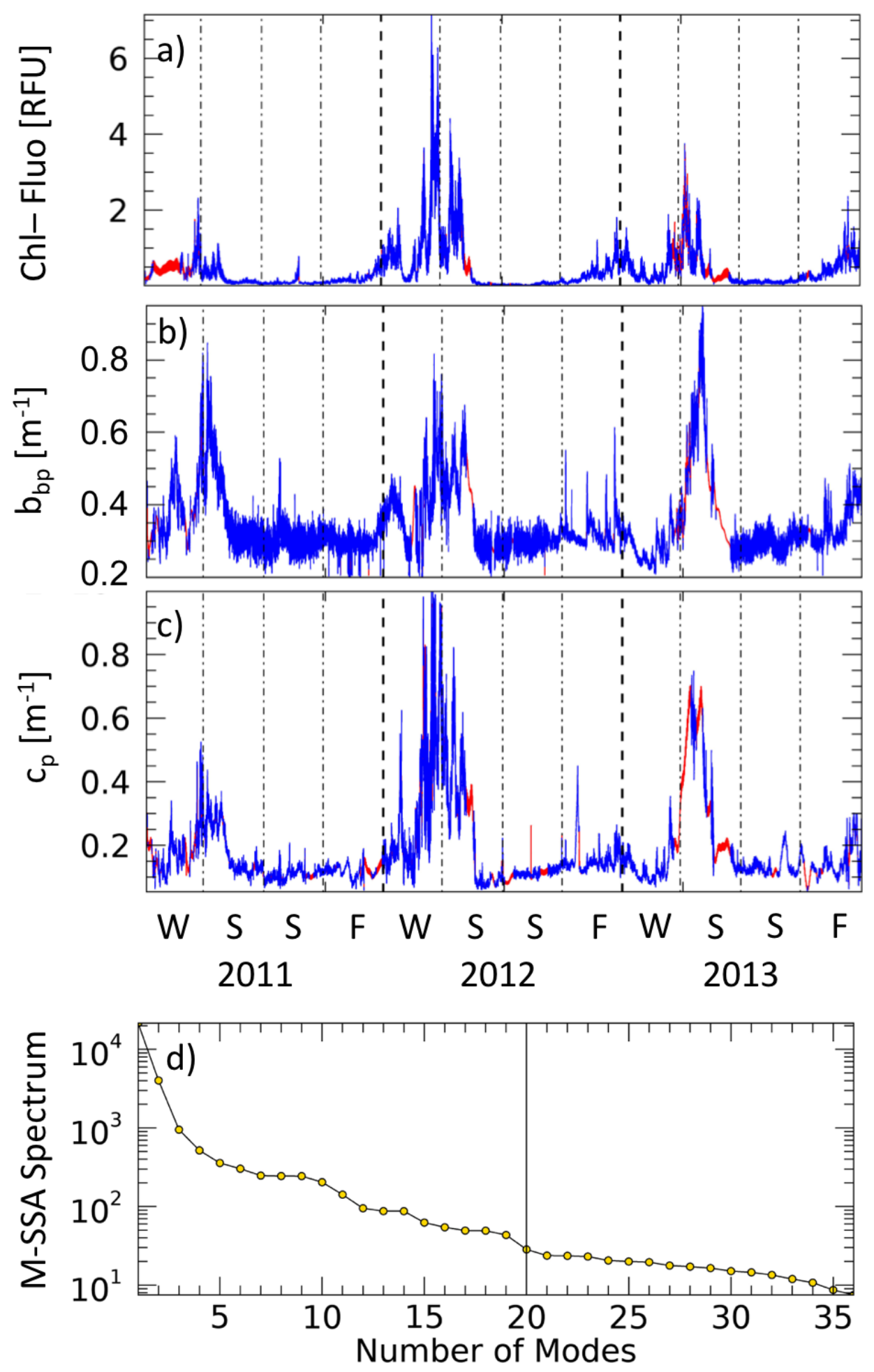

Figure 2: Time-series of Chl-Fluo (a), $b_{b p}(b), c_{p}(c)$ for $2011-2013$ at the BOUSSOLE site. Original data are displayed with blue lines, while the gaps-filled by the M-SSA technique are highlighted with red lines. The letters $\mathrm{W}$ stands for winter, $\mathrm{S}$ for spring, $\mathrm{S}$ for summer and $\mathrm{F}$ for fall. Panel $\mathrm{d}$ is the M-SSA spectrum of filled time-series with the break of the slope spectrum at 20 . 


\subsection{Wavelet analysis}

Since it was first introduced by Morlet (1982; Part I and II), WA has been widely applied to different fields of science. The main characteristic of the WA lays on the decomposition timeseries, and its time-scale localization and amplitude. Usually, a signal of the series can be decomposed into different harmonic components using, for example, the Fourier method. This can be defined as a partition of the variance of the series into its different oscillating components with different frequencies (i.e. the periods). The spectral frequency analysis based on the widely-used Fourier method makes the assumption that the statistical properties of the time-series do not vary with time, being stationary and constant. In such a context, the oceanographic processes do not respect the stationary assumption, and there are evidences of the non-stationary nature of biooptical properties (e.g. $b_{\mathrm{bp}}$ or $\mathrm{c}_{\mathrm{p}}$ ) along a single year (Antoine et al., 2011; Gernez et al., 2011; Dall'Olmo et al., 2012; Barnes et al., 2014; Kheireddine et al., 2014). But, the WA overcomes this problem of non-stationary conditions by performing a local time-scale decomposition of the signal. Thus, WA provides time-dependent spectra (Lau and Weng 1995; Torrence and Campo, 1998, Percival and Walden, 2000; Ampe et al., 2014). This approach helps to track how the different scales are related to the periodic components of the signal. WA is applicable to stationary or nonstationary time-series and quantifies correlation between two signals (Daubechies, 1992; Lau and Weng 1995; Cazalles et al., 2008; Garcia-Reyes et al., 2013). Figure 3 gives an example of application of WA to a stationary synthetic signal and provides elements to interpret the results obtained by this analysis as well as definition of the main WA indexes.

Additionally, in order to understand which are the main dominant cycles that explain the variability on a three-year's time-series, the coefficient AWP* is computed as follows:

$$
A W P_{k}^{*}=\frac{A W P_{\text {period }}}{A W P_{\text {maximum }}}
$$

$A W P_{k}^{*}$ is, thus, the ratio between the average wavelet power ( $A W P_{\text {period }}$; Table 1$)$ of each local maximum with respect to the absolute AWP maximum for each parameter $k\left(A W P_{\text {maximum }}\right.$; Table 1). The ratios allow the rank of cycles for each parameter evaluating which cycles are the most important (values approximately 1) and which are not (values close to 0 ).

A cross-wavelet analysis (CWA) has also been applied to paired bio-optical coefficients time-series at BOUSSOLE site, which allows identification of the temporal relationship between the cycles of the bio-optical properties. The CWA is fundamentally a comparison between the spectra of two time-series, $x(t)$ and $y(t)$ (Chatfield, 1989), sampled with the same time step. It results in a quantity, the cross-wavelet coherence, which can assume values between 0 and 1, indicating the crosscorrelation between the spectra of two time-series, as a function of the period. The most important information obtained by CWA is the identification of the portions of $x(t)$ that covaries with $y(t)$ at specific periods. An output from CWA, coupled to the wavelet coherence spectra (WCS), is its time-average (the average coherence; $\mathrm{AC}$ ). The $\mathrm{AC}$ is equal to 1 when there is a perfect linear relationship at particular periods between the two time-series spectra. In this work, the CWA has been used to investigate the strength of the relationship between bio-optical properties at different temporal scales (e.g. Figs. 6, 9, 10,11) and to understand the relative phases between the timeseries. For more information about the theoretical background and applications of WA and CWA see Torrence and Combo, (1998) and Cazalles et al., (2008). 
a)

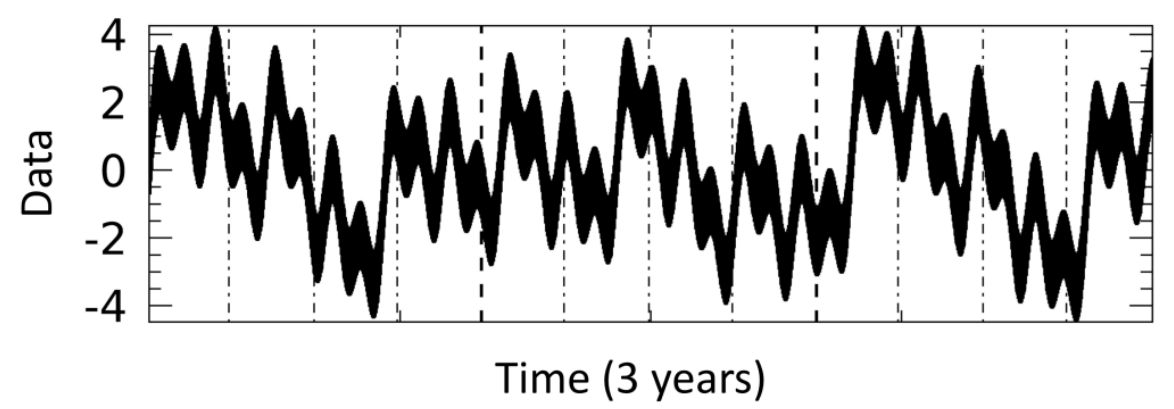

b)

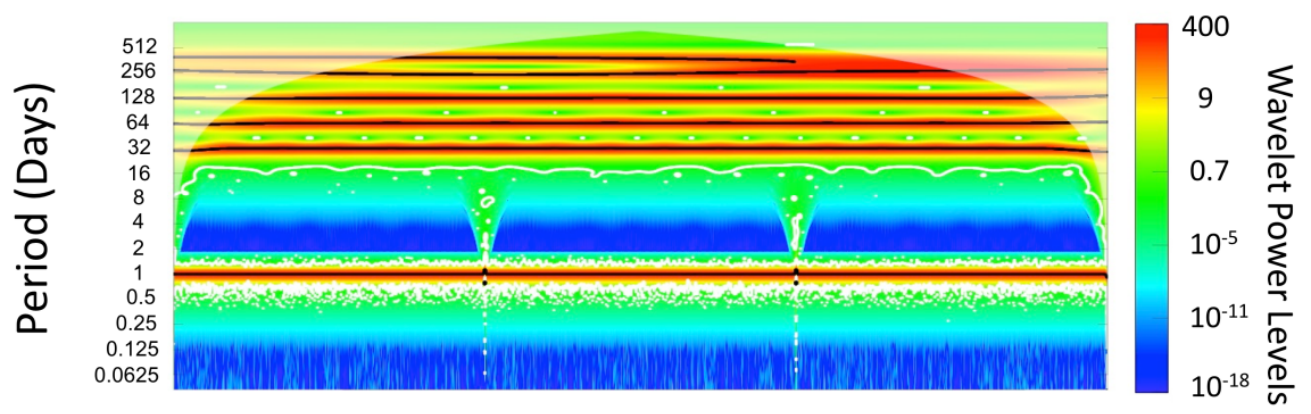

c)

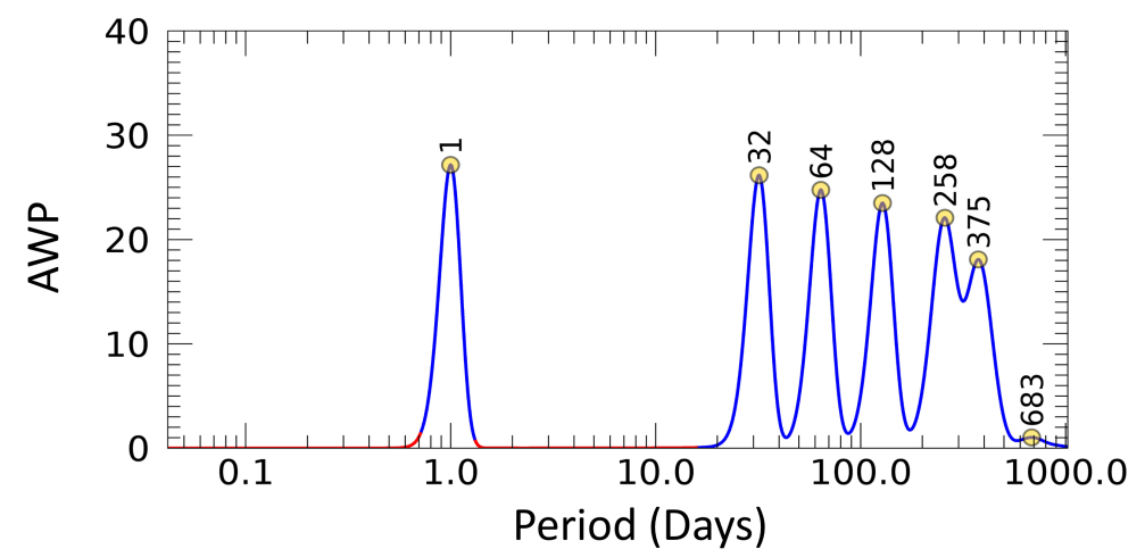

Figure 3: Theoretical example of a three-year time-series of data at 15 minutes' interval, built by overlapping 6 continuous sinusoids at 1, 32, 64, 128, 256 and a two-year 365 days' cycles (a). The wavelet power spectrum (WPS) resulting from the WA is shown in (b) as a function of time. The $y$ axis is the period and colors indicate the power levels of the time-series (high levels in red and low levels in blue). The time-series has a strong (cyclical) signal for the periods and duration of time in correspondence of the black lines in the WPS. The shaded area has not to be considered as it might provide false periodic events (Torrence and Compo, 1998). The thin white contours surrounding regions of stronger variance in the spectra indicate coherent time-frequency regions that are significant (i.e. $>95 \%$ significance). Panel c shows the average of WPS which is the average of the power levels for each period over the whole time-series. Local maxima in the AWP (yellow dots) indicate periods contributing significantly to the variance of the time-series, providing an efficient method to detect and identify periodicities, if present. In red are highlighted periods, and correspondent AWP, with low statistical significance (less than 95\%; Roesch and Schmidbauer, 2014). 


\begin{tabular}{|l|l|}
\hline Acronym & Definition \\
\hline Chl & Chlorophyll Concentration $\left(\mathrm{mg} \mathrm{m}^{-3}\right)$ \\
\hline $\mathrm{b}_{\mathrm{bp}}(\lambda)$ & Particulate backscattering coefficient $\left(\mathrm{m}^{-1}\right)$ \\
\hline$c_{\mathrm{p}}(\lambda)$ & Beam attenuation coefficient $\left(\mathrm{m}^{-1}\right)$ \\
\hline Chl-Fluo & Chlorophyll-Fluorescence $(\mathrm{RFU})$ \\
\hline M-SSA & Multi-Channel Singular Spectral Analysis \\
\hline W & Window Length $\left(\mathrm{N}^{\circ}\right.$ of observations $)$ \\
\hline M & Components \\
\hline WA & Wavelet Analysis \\
\hline CWA & Cross-Wavelet Analysis \\
\hline WPS & Wavelet Power Spectra \\
\hline AWP & Average Wavelet Power \\
\hline AWP* & Average Wavelet Power Ratio \\
\hline WCS & Wavelet Coherence Spectra \\
\hline AC & Average Coherence \\
\hline
\end{tabular}

Table 1: Symbol and acronym definitions.

\section{Results}

This section starts from the description of each time-series, throughout the detection of the intraannual dominant temporal patterns, and ends with the description of the changes of the main cycles over time and the definition of the temporal relationships between the different cycles of the biooptical properties here studied.

\subsection{Description of the time-series}

The time-series of each parameter whose gaps are filled by using the M-SSA technique are shown in Figure 2. The $b_{b p}$ and $c_{p}$ range of variation is respectively between $10^{-4} \mathrm{~m}^{-1}$ and $10^{-3} \mathrm{~m}^{-1}$ and between $0.1 \mathrm{~m}^{-1}$ and $1.0 \mathrm{~m}^{-1}$ with minima occurring in the summer/fall (i.e. oligotrophic season) and maxima occurring in the winter/spring (i.e. mesotrophic season), respectively (Figure 2). The ChlFluo annual signal ranges between 0.012 RFU, in summer/fall, up to 7.5 RFU in winter/spring.

\subsection{Dominant temporal patterns}

Figure 4 and Table 2 display the AWP after the wavelet analysis on the three time-series, and the correspondent AWP*. For the Chl-Fluo nine relative maxima (yellow circles in Figure 4a) emerge at periods of approximately 351,200,124, 46, 31, 21, 10, 3 and 1 days, indicating nine major patterns of the Chl-Fluo variability. The AWP spectrum for $b_{b p}$ shows seven relative maxima at $370,193,126,58,16,11,2$ days. Finally, for the $c_{p}$ relative maxima at 372, 192, 130, 57, 27, 15, $11,4,2,1$ days are detected. In both cases of $b_{b p}$ and $c_{p}$, two additional maxima are found at 979 and 911 days, respectively. These relative maxima have low AWP $(<1)$ and are related to periods exceeding the upper limit that can be significantly retrieved in this study (i.e. 1 year).

For brevity, periods close to 365 days are interchanged with the term "annual", close to 180-days with "6-months", close to 128-days with "4-months".

\subsection{Wavelet Power Spectra}

313 The WPS of Chl-Fluo (Figure 5a) reveals a persistent annual periodicity, thereby explaining the greatest amount of variability. Accordingly, the AWP value shows its maximum (30.8) at this 
period (Table 2) with two secondary maxima at 4-months and at 6-months, both accounting for half of the variability with respect to the annual periodicity (14.6 and 15.6 respectively; Table 2). In the case of $b_{b p}$, the annual cycle has an AWP value of 24.3. The most dominant patterns are associated to the 6-month cycle with an AWP of 29.7, and 4-month cycle with AWP of 24.3 (Figure 4). A significant cycle is also present with a period of 58 days (AWP value of 11.0). The WPS (Figure 5b) highlights a range between 11 and 16 days, particularly evident at the winter-to-spring transitions, with a clear inter-annual variability and the AWP value for this cycle is less than 5 (Figure 4). For cycles between 0.5 and 2 days, the AWP is generally lower, yet not zero, indicating that some periodicity for $b_{b p}$ at these scales exists though with limited impact on the overall variability (Table 2). Cycles less than 2 days also have less statistical significance along the three years of data.

The $c_{p}$ cycles at 4-months, 6-months, and 1-year periods are observed in the WPS (Figure 5c), resulting in AWP values of 20.3, 33.0 and 31.8, respectively (Figure 4 and Table 2). Other relative maxima have average values less than 6. The WPS (Figure 5c) also highlights 1, 2, 4, 11-15, 27 and 57 day cycles, evident at the transition from winter to spring of 2012. For the period at 1 day, the AWP is low, though greater than zero, and still statistically significant, indicating that some $\mathrm{c}_{\mathrm{p}}$ variability at this scale exists (Table 2).

The signal of the annual cycle covers all seasons for all parameters (Figure 5), which have maxima at a particular moment of the year: always in winter and spring (Figure 2 and Figure 5). The 6month period is the dominant pattern in the case of $b_{b p}$ and $c_{p}$, and is the second dominant pattern in the Chl-Fluo time-series. The 4-month cycle shows a considerable magnitude for $b_{b p}$ and $c_{p}$, but is limited for Chl-Fluo (Table 2). Moving to the lowest temporal cycles, Figure 5 shows how diel cycles are detectable for most of the three time-series, confirming the importance of this temporal scale, especially for Chl-Fluo and $\mathrm{c}_{\mathrm{p}}$ time-series. Summarizing, Chl-Fluo shows a strong annual cycle signal along the entire time-series, but particularly from spring 2011 to winter 2013 considering only the lightened areas (Figure 5a). The year 2012 (more specifically from winter 2011 to spring 2013) shows a strong cyclic nature at periods greater than 1 week. WPS of $b_{b p}$ shows high power levels from 128 to 365 day periods (Figure 5b). However, for periods lower than 64-days, the strength of the WPS is high only during spring and winter.

Contrarily, WPS of $c_{p}$ (Figure 5c), shows evident inter-annual variability yet not all the temporal footprints (i.e. periods) have high values in 2011 and 2013. Dominant cycles are persistent at higher temporal scales from 2011 to 2013, whereas periods lower than 64 days are dominant only in the winter and spring in agreement with the other bio-optical properties. The Chl-Fluo AWP is also characterized by two relative maxima in correspondence with 46 and 124 days (Table 2), occurring only in the mesotrophic periods of the year (winter - spring of 2012; Figure 5a). The AWP of $b_{b p}$ shows relevant cycles also at the 11-16, 58 and 126 day periods occurring in the most productive periods of the year of $2011-2013$ (winter and spring). Furthermore, the 126-day cycle has a strong influence on the entire time-average spectrum (Figure 4 and $5 b$ ). In case of $c_{p}$, there is a relevant cycle at 130 days. All these cycles have strong signals during the winter and spring seasons (Figure 5). In such a context, Figures 6 illustrates the AC obtained with the CWA between the different bio-optical coefficients along the entire 3-year timeseries of observations. A high correlation $(>0.8)$ between the periodicities of bio-optical coefficients greater than 10 days is observed (Figure 6). Periodicity at these scales has been poorly represented in the literature, and with the use of WA all of these cycles can be retrieved and 
described. Figure 5 displays evident cycles in winter 2012 for all parameters (black lines; i.e. a productive period), and, therefore, it is an optimum case of study to highlight those lesser-known cycles, such as the intra-seasonal cycles (i.e. diel, weekly, monthly). In order to complement the analysis, an opposite case of study has been analyzed by applying a specific WA on summer 2012, i.e. the most oligotrophic period. Moreover, in these seasons, the diurnal variance of parameters is, in general, the highest in winter and the lowest in summer (not shown). Finally, the selected data sets have a limited number of missing observations (less than $11 \%$ in both winter and summer seasons), restricting the use of reconstructed measurements.

In order to highlight the mid and short-term variability, a specific WA has thus been applied to two selected seasons of the time-series: winter and summer 2012 (Figures 7 and 8). Figure 7 shows the AWP obtained by WA on winter 2012 and Table 3 contains the AWP* values correspondent to the maxima. For the $b_{b p}$, four significant maxima are retrieved (yellow circles in Figure 7a) at periods of $17,10,5$ and 1 days indicating four major patterns of $b_{b p}$ variability in this season. There is also a 12 hour cycle that emerges from the analysis, but with reduced statistical significance in respect to other cycles (less than 95\%). The $c_{p}$ AWP shows five relative maxima at 29, 12, 3, 2, and 1 days. A diel cycle is evident and represents the third maximum even if with a low AWP. Ultimately, for the Chl-Fluo, detected relative maxima are 29, 18, 11, 3 and 1 days. In winter, the dominant temporal patterns are of cycles greater than 10 days for all three parameters.

The opposite season, summer, is the counterpart case of study. This is the period of lowest productivity along the entire year at BOUSSOLE site. Figure 8 shows a time-series for each parameter and the corresponding AWP and AWP* (Table 4). For the $b_{\mathrm{bp}}$ different maxima emerged (yellow circles in Figure 7a) in correspondence to 18, 10, 7, 4, 2, 1 days and 12 hours indicating these cycles as the main driven temporal patterns of variability during the season. The diel cycle is the second important temporal pattern for this coefficient. The $c_{p}$ AWP shows five relative maxima at 23, 10, 4, 3, 1 days. The diel cycle is the most dominant for $c_{p}$ in summer (AWP of 22.0). Lastly, the Chl-Fluo has eight relative maxima at 22, 12, 8, 4, 3, 1 days and 12 hours and the diel cycle is the most significant local pattern. One could argue that, during summer, the quenching effect can dominate and drive the diel cycle of Chl-Fluo. Therefore, this has to be taken into account in the interpretation of the results for the Chl-Fluo diel cycle (Xing et al., 2017).

\subsection{Cross-Wavelet Analysis}

The Chl-Fluo vs $b_{b p}$ time-series have high $\mathrm{AC}$ values for periods ranging from 1 day $(\cong 0.7)$ to 1 year $(\cong 1)$. At lower scales, there is a high correlation only during the winter and spring (Figure 9). This is also true for the Chl-Fluo vs $c_{p}$ and the $c_{p}$ vs $b_{b p}$ time-series which have coherence values 0.7 and 0.8 for the 1 day period, respectively, and up to 1 at the annual scale. At periods lower than 1 day, the correlation between the three bio-optical parameters is low $(<0.5)$. The Chl-Fluo to $c_{p}$ coherence analysis reveals that the correlation is higher at daily scales $(>0.7)$ with respect to ChlFluo/ $b_{\text {bp }}$. The AC value is higher with respect to Chl-Fluo and $b_{b p}$. This is confirmed by what is expected about the relationship between $b_{\mathrm{bp}}$ and phytoplankton cells (Loisel et al., 2001; Stramski et al., 2004, Dall'Olmo et al., 2009; 2012). 

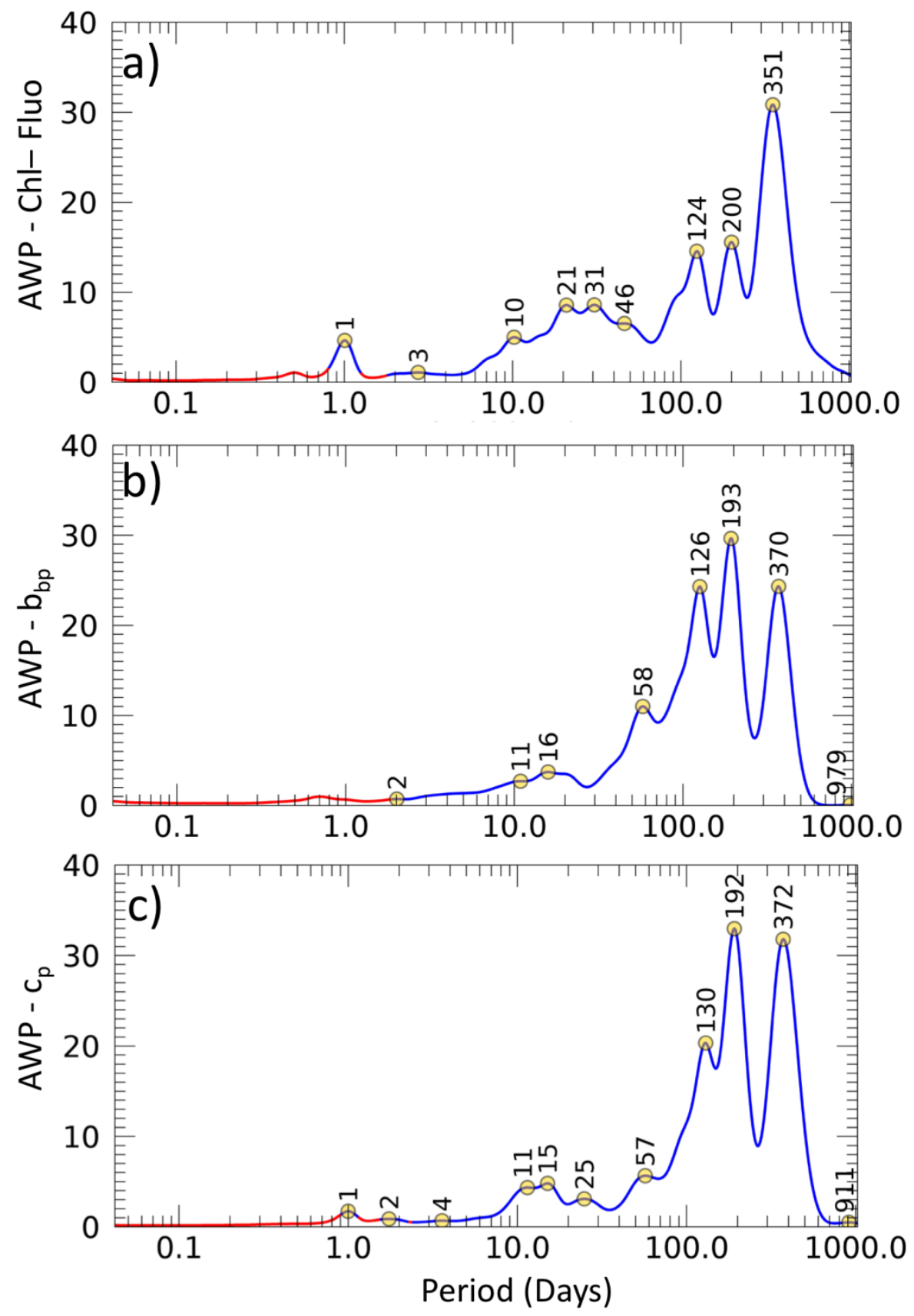

400 Figure 4: AWP of the Chl-Fluo (a), $b_{b p}(b)$ and $c_{p}(c)$. The statistical significance is $95 \%$ in case of the 401 highest temporal scales, from day to annual scales, for each parameter (blue line). At the lowest temporal scales, the significance is lower than $95 \%$ (red line) and the results have to be interpreted with caution. The statistical significance is computed following Roesch and Schmidbauer (2014). Yellow dots are the relative local maxima for the single parameter with also information of the exactly days.

\begin{tabular}{|c|c|c|c|c|c|c|c|c|c|c|c|c|}
\hline Period (days) & 351 & 200 & 124 & - & 46 & 31 & 21 & - & 10 & 3 & - & 1 \\
\hline$A W P_{C h l-F l u o}^{*}$ & $\mathbf{1 . 0}$ & 0.50 & 0.47 & - & 0.21 & 0.27 & 0.27 & - & 0.16 & 0.05 & - & 0.15 \\
\hline Period (days) & 370 & 193 & 126 & 58 & - & - & - & 16 & 11 & - & 2 & - \\
\hline$A W P_{b_{b p}^{*}}^{*}$ & 0.82 & $\mathbf{1 . 0}$ & 0.82 & 0.37 & - & - & - & 0.13 & 0.09 & - & 0.02 & - \\
\hline Period (days) & 372 & 192 & 130 & 57 & - & - & 25 & 15 & 11 & 4 & 2 & 1 \\
\hline$A W P_{c_{p}}^{*}$ & 0.96 & $\mathbf{1 . 0}$ & 0.62 & 0.17 & - & - & 0.09 & 0.15 & 0.13 & 0.02 & 0.03 & 0.05 \\
\hline
\end{tabular}

Table 2: AWP* from the AWP of each parameter. Numbers in bold indicate the dominant cycles. 

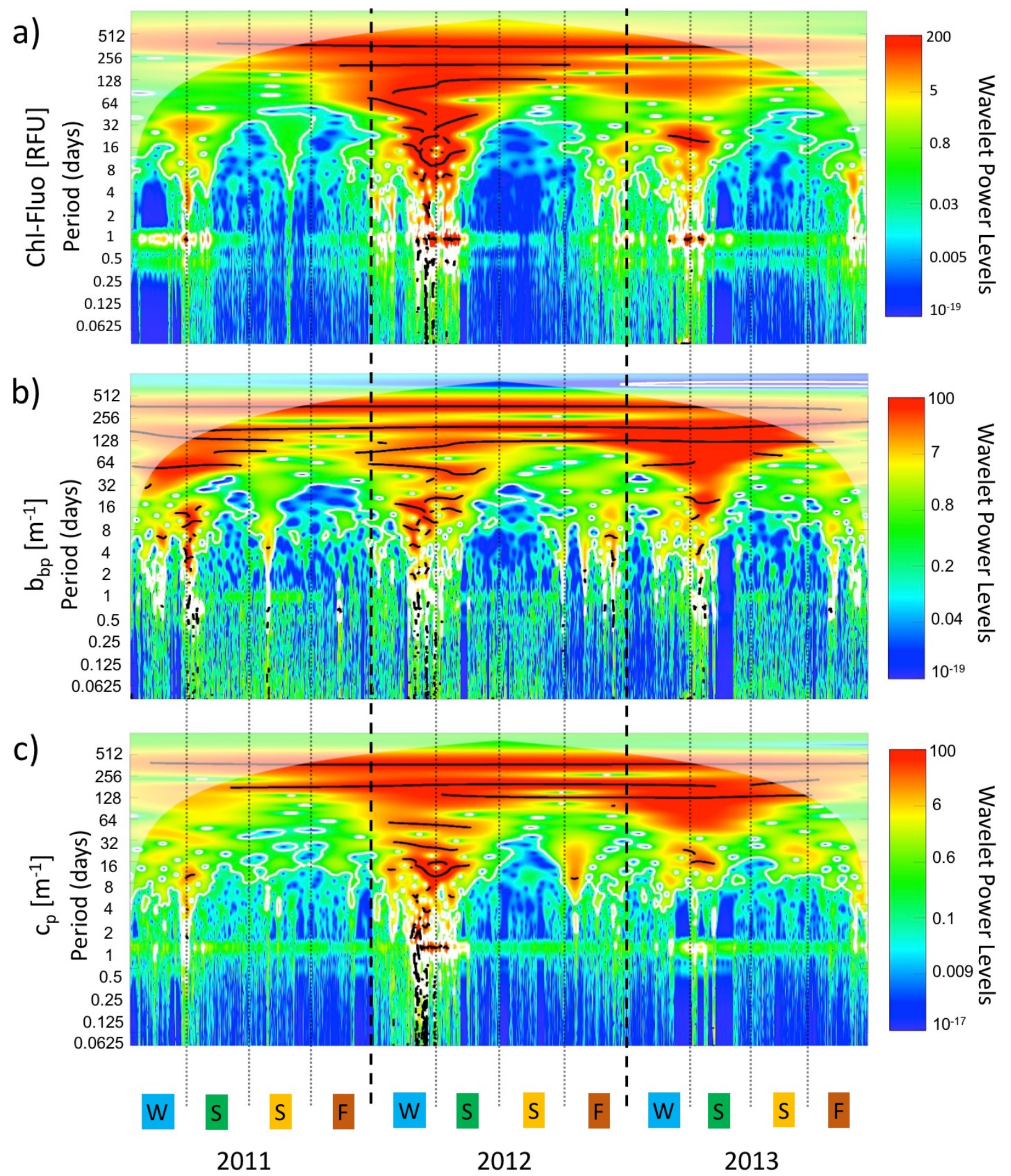

Figure 5: WPS for Chl-Fluo (a), $b_{b p}(b)$ and $c_{p}(c)$. The letters $W$ stands for winter (in blue), $\mathrm{S}$ for spring (in green), $\mathrm{S}$ for summer (in orange) and $\mathrm{F}$ for fall (in brown). The time-series has a strong (cyclical) signal for the periods and duration of time in correspondence of the black lines in the WPS. The shaded area has not to be considered as it might provide false periodic events (Torrence and Compo, 1998). The thin white contours surrounding regions of stronger variance in the spectra indicate coherent time-frequency regions that are significant (i.e. 95\% significance). The significance test is computed following Roesch and Schmidbauer 414 (2014). 


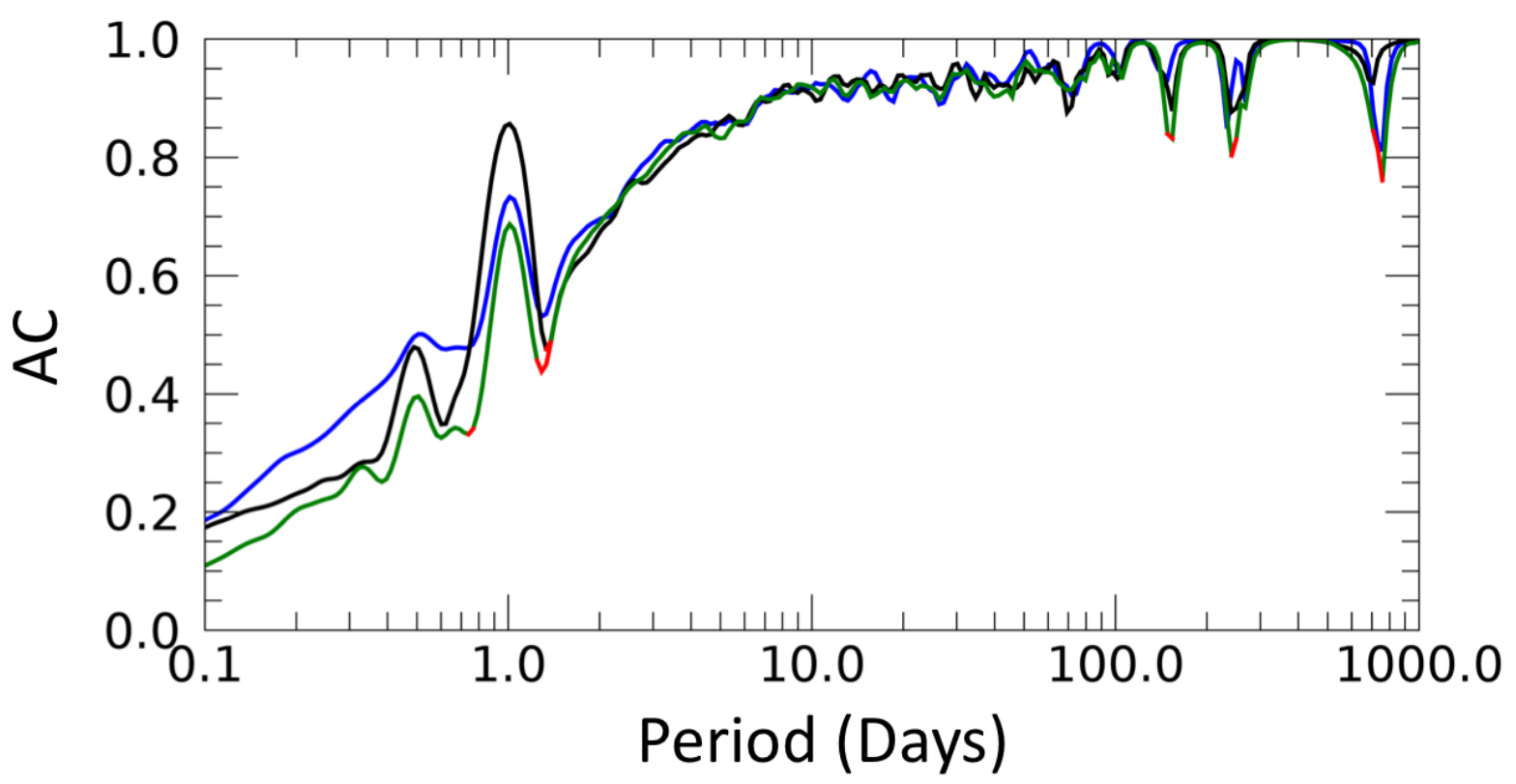

Figure 6: AC obtained from the CWA between paired bio-optical properties: Chl-Fluo vs. $b_{b p}$ (green line), Chl-Fluo vs. $c_{p}$ (black line) and $b_{b p}$ vs. $c_{p}$ (blue line). In red are highlighted periods where the AC is with low statistical significance (less than 95\%).
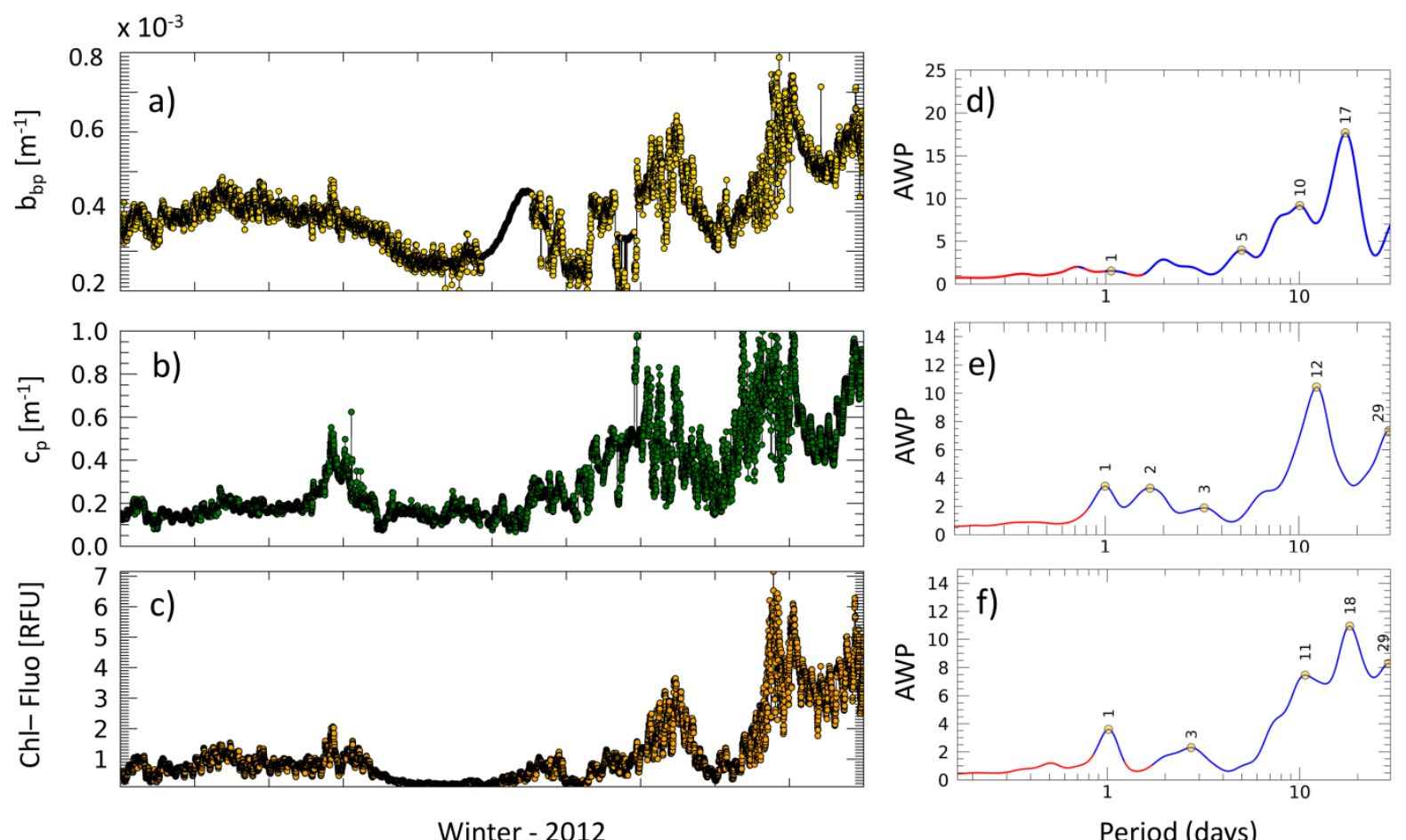

Winter - 2012

Period (days)

Figure 7: Time-series of $b_{b p}(a), c_{p}(b)$ and Chl-Fluo (c) in Winter 2012. AWP of $b_{b p}, c_{p}$, Chl-Fluo are in panels d, e, f. Red lines are located where the statistical significance is less than $95 \%$ and the results have to be interpreted with caution. The significance test is computed following Roesch and Schmidbauer (2014). 


\begin{tabular}{|c|c|c|c|c|c|c|}
\hline Period (days) & - & 17 & 10 & 5 & - & 1 \\
\hline$A W P_{b_{b p}^{*}}^{*}$ & - & $\mathbf{1 . 0}$ & 0.52 & 0.23 & - & 0.09 \\
\hline Period (days) & 29 & - & 12 & 3 & 2 & 1 \\
\hline$A W P_{c_{p}}^{*}$ & 0.70 & - & $\mathbf{1 . 0}$ & 0.18 & 0.31 & 0.33 \\
\hline Period (days) & 29 & 18 & 11 & 3 & - & 1 \\
\hline$A W P_{C h l-F l u o}^{*}$ & 0.76 & $\mathbf{1 . 0}$ & 0.68 & 0.21 & - & 0.33 \\
\hline
\end{tabular}

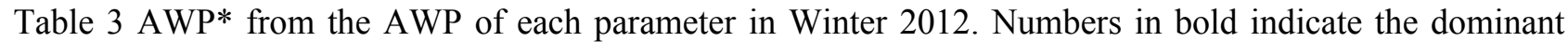
cycles.
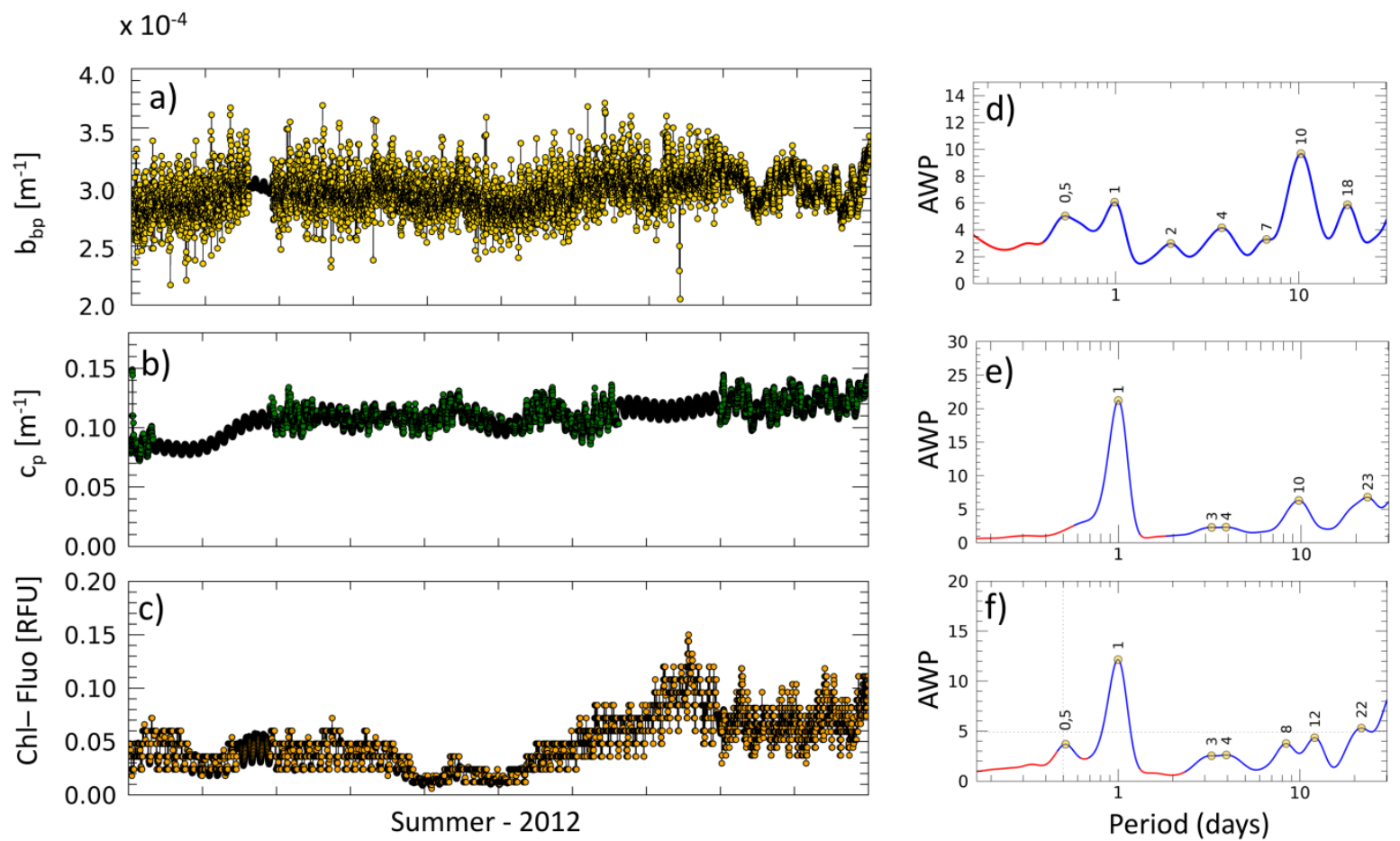

Figure 8: Time-series of $b_{b p}(a), c_{p}$ (b) and Chl-Fluo (c) in Summer 2012. AWP of $b_{b p}, c_{p}$, Chl-Fluo are reported in panels $d, e, f$. Red lines are located where the statistical significance is less than $95 \%$ and the results have to be interpreted with caution. The significance test is computed following Roesch and Schmidbauer (2014).

\begin{tabular}{|c|c|c|c|c|c|c|c|}
\hline Period (days) & 18 & 10 & 7 & 4 & 2 & 1 & 0.5 \\
\hline$A W P_{b_{b p}^{*}}^{*}$ & 0.61 & $\mathbf{1 . 0}$ & 0.34 & 0.43 & 0.31 & 0.63 & 0.52 \\
\hline Period (days) & 23 & 10 & - & 4 & 3 & 1 & - \\
\hline$A W P_{c_{p}}^{*}$ & 0.32 & 0.30 & - & 0.11 & 0.11 & $\mathbf{1 . 0}$ & - \\
\hline Period (days) & 22 & 12 & 8 & 4 & 3 & 1 & 0.5 \\
\hline$A W P_{\text {Chl }}^{*}$ Fluo & 0.44 & 0.36 & 0.31 & 0.22 & 0.21 & $\mathbf{1 . 0}$ & 0.30 \\
\hline
\end{tabular}

Table 4: AWP* from the AWP of each parameter for Summer 2012. Numbers in bold indicate the dominant cycles. 


\subsection{Annual cycle}

The most generally observed pattern was a phytoplankton maximum in the winter/spring season, minimum in summer and a successive increase in fall season, that corresponds to a typical annual cycle of a temperate ocean, as already reported for the north-western Mediterranean Sea (Antoine et al., 2011; D'Ortenzio et al., 2014).

The main pattern revealed by WA applied to BOUSSOLE data is the periodicity of the seasonal evolution: from late fall to early spring (essentially the winter) where there is always a convergence of Chl-Fluo, $b_{b p}$ and $c_{p}$ signals (Figures 5 and 9).

The spring bloom in the Ligurian Sea is regulated by the increase of light availability after the winter mixing of the water column that redistributes nutrients from deep to surface waters (Antoine et al., 2011; D'Ortenzio et al., 2014). The phasing, duration and intensity of the annual bloom varies from year to year, with a stronger bloom in 2012 in respect to 2011 and 2013 (Figure 2; Mayot et al., 2016). This variability arises from the range of the processes controlling bloom dynamics, including physical forcing such as meteorological extreme events, and/or interaction between different species of phytoplankton organisms (Winder et al., 2010).

During summer, the increase of light availability causes the decrease of intra-cellular photosynthetic pigments concentration need and, concurrently, the low nutrient availability limits the phytoplankton population growth and its abundance stays low (Bellacicco et al., 2016). The $b_{\text {bp }}$ and $\mathrm{c}_{\mathrm{p}}$ are characterized by a similar temporal pattern in summer (Figure 2 and 5). During fall, as light availability decreases and mixed layer deepens, phytoplankton concentration increases again.

The $b_{b p}$ and $c_{p}$ time-series are coherent with the Chl-Fluo time-series at annual scale because both $\mathrm{b}_{\mathrm{bp}}$ and $\mathrm{c}_{\mathrm{p}}$ are sensitive to particle size ranges that include phytoplankton (Stramski et al., 2004; Sosik et al., 2008; Organelli et al., 2018), thus phytoplankton cells abundance strongly impacts the variability of $b_{b p}$ and $c_{p}$. Figures 6 and 9 reveal how the bio-optical properties have a WCS and AC close to 1 at annual scale along the entire time-series. In detail, Chl-Fluo is in advance in respect to the annual signal of $b_{b p}$ (Figure 9a), while with $c_{p}$ they are in phase (Figure $9 b$ ). The $c_{p}$ leads in respect to the $b_{b p}$ annual signal as highlighted by the arrows in the Figure 9c. In such a context, the maximum of Chl-Fluo is in shift in advance of approximately 20 days with respect to $c_{p}$ and $b_{b p}$ (Figure 4 and Table 2). This could be attributed to the inter-annual variability (low bloom maxima in 2011 and two maxima in 2013 for Chl-Fluo) which determined a dephasing in the AWP. Another reasonable explanation can be that the Chl-Fluo annual maximum (independently of its strength) is not occurring always at the same time (i.e. indeed there are four maxima in the Chl-Fluo timeseries: March in 2011 and 2012, April and December in 2013; Figure 2). Nevertheless, there is a good coherence between the parameters at annual temporal scales ( $\mathrm{AC} \cong 1$; Figure 6).

\subsection{Six- and four- month cycles}

Other fundamental cycles retrieved by WA are at 6 months and 4 months. The 6-month cycle is unexpectedly the most important cycle in cases of $b_{b p}$ and $c_{p}$, while for Chl-Fluo it is second in terms of dominance. The 4-month cycle is the third important cycle for all of the parameters, especially for $b_{b p}$ (Table 2). AC shows a strong correlation of the WPS for all combinations of biooptical coefficients at these periods ( $\cong 1$; Figures 6 and 9 ). The 6-month cycle is dominant for $b_{b p}$ and $c_{p}$, whereas it has a lower strength for the Chl-Fluo, a consequence of the inter-annual variability of its WPS (Figure 5a). The 6- and 4-month cycles are interpreted here as mainly due to 
the winter-to-spring modification of the mixing intensity (D'Ortenzio et al., 2005), nutrient and light availability, grazing and shift in phytoplankton community structures (Mignot et al., 2014; Sammartino et al., 2015). Bellacicco et al., (2016) highlight that the use of Chl as a proxy of phytoplankton biomass, as well as Chl-Fluo, is strictly influenced by intracellular processes, especially in intermediate seasons, such as late spring and early fall. Alternately, $b_{b p}$ and $c_{p}$ are sensitive to the abundance of phytoplankton cells and non-algal particles, as well as particle size distribution, refractive index, and the shape and structure of particles in the seawater. Therefore, in these intermediate periods, where the Chl-Fluo signal is low while $c_{p}$ and $b_{b p}$ are relatively high, the 6-month cycle signal detection could be reduced impacting total seasonal and annual cycles. For example, in early fall, there are low nutrients and low light conditions and the result is an increase of phytoplankton cells, as indicated by the increase of $c_{p}$ and $b_{b p}$, however phytoplankton does not have a high concentration of photosynthetic pigment, and consequently a low Chl-Fluo. In late spring, the photoacclimation process is particularly relevant and impacts on Chl-Fluo due to high nutrients and high light availability. The $b_{b p}$ and $c_{p}$ proxies are not affected by the phytoplankton physiological state (Bellacicco et al., 2016; Barbieux et al., 2018) and the effect of the carbon accumulation in phytoplankton cells dominates the $c_{p}$ and $b_{b p}$ WPS (Figures 4 and $5 b$, c), while the physiological signal (i.e. photoacclimation) has an effect on the strength of the signal in WPS of the Chl-Fluo signal (Figures 4 and 5a). Figure 9 displays how $c_{p}$ signal is in advance with respect to $b_{b p}$ at 6 month cycles along 2012 and 2013. On the other hand, the $b_{b p}$ signal is in delay in respect to Chl-Fluo in 2012, while with $c_{p}$ they are in phase from summer 2011 to spring 2012. Figure 9 also shows the relationship between parameters at the period of 4-months. In this period, Chl-Fluo signal is delayed in respect to $c_{p}$ as in the case of 6-months, while $c_{p}$ signal seems to be in advance compared to the $b_{b p}$ signal. From the analysis, the intensity of a 4-month cycle differs in cases of Chl-Fluo in respect to $b_{b p}$ and $c_{p}$ (Table 2). 

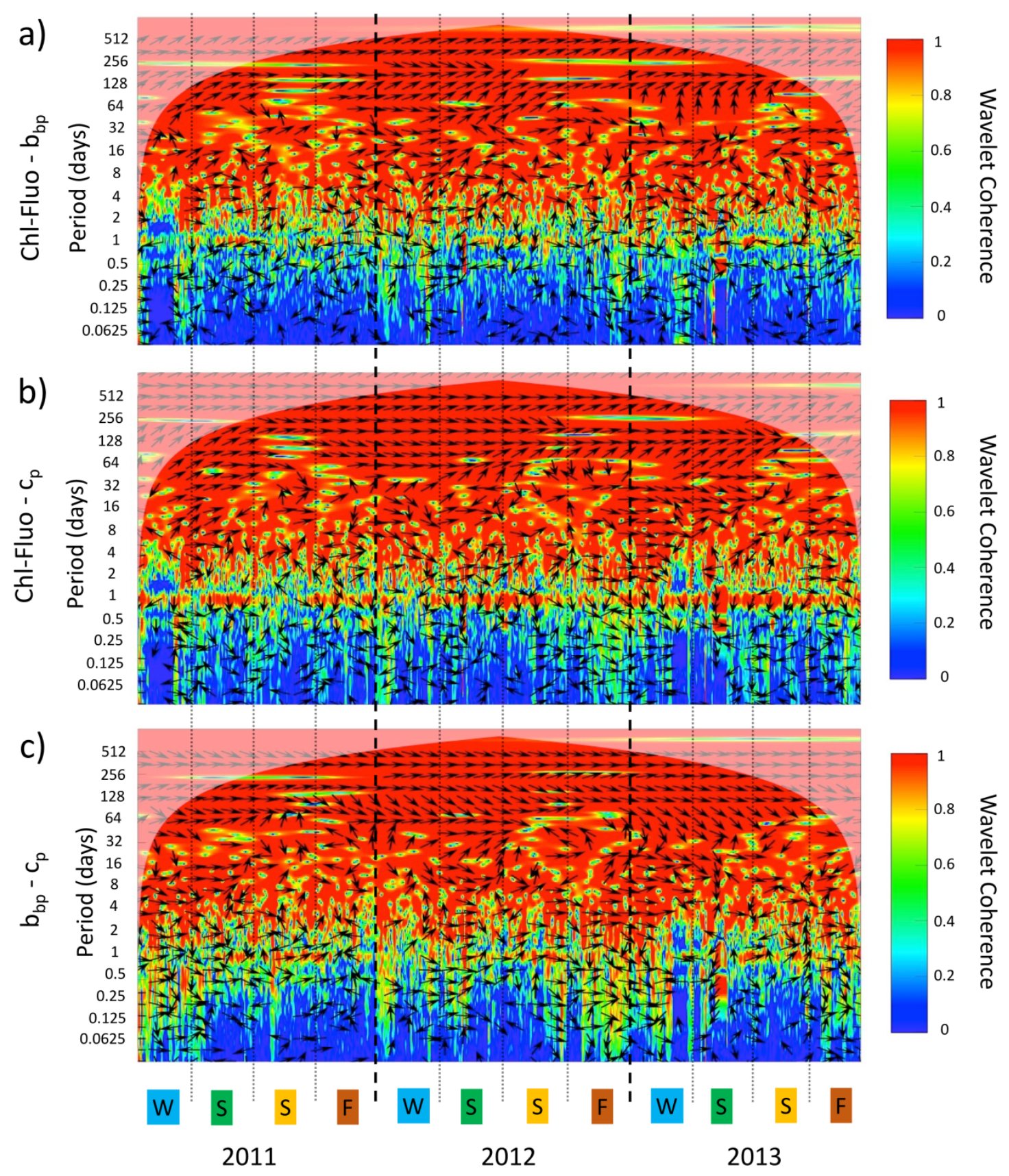

Figure 9: Cross-wavelet coherence spectra between (a) Chl-Fluo and $b_{b p}$, (b) Chl-Fluo and $c_{p}$, and (c) $b_{b p}$ and $c_{p}$ at BOUSSOLE site. Color indicates the level of covariability between the time-series (values between 0 and 1); arrows denote the relative phase between the time-series (right: in phase; left: antiphase; up or down: one series leads the other by $\left.90^{\circ}\right)$ with significance covariability $(>95 \%)$. Shaded area has not to be considered as it might provide false periodic events (Torrence and Compo, 1998). The letters W stands for winter (in blue), $\mathrm{S}$ for spring (in green), $\mathrm{S}$ for summer (in orange) and $\mathrm{F}$ for fall (in brown), as for Figure 5.

\subsection{Intra-seasonal variability: mid- and short-term cycles}

WA detected relevant cycles at scales other than annual, 6- and 4-months are interpreted here as caused by intra-seasonal (i.e. from diel to monthly) variability of the examined bio-optical parameters: the highest cycles are defined as mid-term cycles, while the lowest as short-term counterparts. In such a context, the specific WA applied to these particular periods of winter and 
summer 2012 enables the detection and power of these additional sources of variability (from 12 hours to 29 days; Tables 3 and 4).

At the beginning of winter and over the 16 day period, $\mathrm{c}_{\mathrm{p}}$ and Chl-Fluo signals are in phase and then $c_{p}$ is in advance compared to the Chl-Fluo footprint. Contrarily, $b_{b p}$ and Chl-Fluo indicators are in phase along the entire season. From 2 day up to 16 day periods, Chl-Fluo is partially in phase with $b_{b p}$ and $c_{p}$, however, some hotspots occur in which both $b_{b p}$ and $c_{p}$ have phase differences in respect to the Chl-Fluo signal. In cases of $b_{b p}$ to $c_{p}$, at these highest periods, $c_{p}$ leads the $b_{b p}$ mark (Figure $10)$.

In summer, at the range of 8-16 days, Chl-Fluo is in advance in respect to the $b_{b p}$ signal, while on the reverse, the Chl-Fluo indicator at this period is delayed with respect to the $c_{p}$. Regarding the $b_{b p}$ to $c_{p}$ relationship, the former is in advance with respect to the latter at the beginning of summer, while at the end of summer, there is an opposite situation of delay. Between 2 and 8 days, Chl-Fluo is not in phase with both $c_{p}$ and $b_{b p}$ signals (e.g. start of summer), while the optical parameters are in phase (Figure 11).

A possible explanation of these mid-term cycles could also be given by episodic phytoplankton biomass increases in response to stochastic events that potentially impact the mixed layer dynamics which are typical of the winter period at the BOUSSOLE site. For instance, as highlighted by Winder et al., (2010), extreme wind events could generate biomass oscillations by temporarily reducing the phytoplankton bloom. In addition, Nezlin et al. (2002) showed, using WA, that shortperiod variations (less than 100 days) of remotely-sensed chlorophyll during spring seasons correlated with surface water, air temperatures and wind stress, that have rapidly varied (i.e. at the intermediate scales that we analyze here). The mechanism of these variations was an intensification of phytoplankton growth resulting from mixing of the water column by wind stress and entrainment of cold, rich in nutrients, water into the euphotic layer. Monteiro et al. (2015) demonstrated the presence of an intra-seasonal variability that is always driven by wind stress and has a temporal scale from daily up to $14-20$ days. These orders of magnitude are consistent with the maxima reported in the AWP plots, for both winter and summer 2012 (Figures 7, 8; Table 3 and 4). The general Chl-Fluo and $\mathrm{c}_{\mathrm{p}}$ WPS also show a clear diel cycle footprint, particularly evident during high biomass periods (winter and spring in Figure 5a and c). On the other hand, the diel signal is less evident for $b_{b p}$ (Figures 4 and $5 b$ and Table 2). The correlation between $c_{p}$ and Chl-Fluo at diel scale (AC greater than 0.7 in Figure 6) is well known during winter and spring, when the particles abundance is dominated by phytoplankton cells (Kheireddine et al. 2014; Bellacicco et al., 2016). The diel changes are generally considered to be driven by specific forcings (Oubelkheir et al., 2005; Oubelkheir and Sciandra 2008; Gernez et al., 2011, Loisel et al., 2011; Barnes et al., 2014; Kheireddine et al., 2014). At diel cycle, the correlation between Chl-Fluo and $b_{b p}$ periodicities is lower $(\cong 0.6)$ than to Chl-Fluo vs. $c_{p}(>0.7)$. A good correlation is found in the $b_{b p} v_{s} c_{p}(>0.7)$. By applying the specific WA over a three-month period both in winter and summer seasons, more information can be gathered about short-term variability, especially on the diel cycle.

During the winter, Chl-Fluo signal is in advance to $c_{p}$ without any phases between parameters despite AC showing high values (Figure 10). Reversely, the $\mathrm{AC}$ between Chl-Fluo and $\mathrm{b}_{\mathrm{bp}}$ is lower (less than 0.5 ) below diel cycle. The AC between $b_{b p}$ and $c_{p}$ is always lower than 0.6 (Figure 10). In the winter, the period of strong mixing and start of the bloom (Barnes et al., 2014, Kheireddine et al. 2014; Bellacicco et al., 2016), $\mathrm{c}_{\mathrm{p}}$ can be increasingly influenced by diel variations of abundance of phytoplankton cells (Oubelkheir et al., 2005, Oubelkheir and Sciandra, 2008), even if 
by a significant seasonal variability. This would confirm that phytoplankton makes a lower contribution to $b_{b p}$ than to $c_{p}$, so their seasonal changes are poorly reflected in overall seasonal changes. $b_{b p}$ is influenced more by the presence of sub-micrometer particles such as detrital particles or heterotrophic bacteria (Morel and Ahn, 1991; Stramski and Kiefer, 1991, Stramski et al., 2004), that do not have a periodical diel cycle. Recently, Organelli et al., (2018) found that another main source of variability on $b_{b p}$ is due to particles with equivalent diameters between 1 and $10 \mu \mathrm{m}$ giving thus new insight into the $b_{\mathrm{bp}}$ coefficient and particles in seawater.

In summer, Chl-Fluo and $b_{b p}$ have an AC of 0.8 but $b_{b p}$ is largely in anti-phase with Chl-Fluo, as expected for this period of year of low productivity. Inversely, $c_{p}$ and Chl-Fluo diurnal signals have an AC value of approximately 1. During this season of absence of high abundance of phytoplankton (Kheireddine et al. 2014; Bellacicco et al., 2016), $\mathrm{c}_{\mathrm{p}}$ can be due to the daily variations of coupled heterotrophic bacteria and particles pool (i.e. phytoplankton cells) which remain within the upper layer caused by the strong stratification of the water column. However, Chl-Fluo diel signal can be determined due to the quenching effect (Xing et al., 2017). In addition, at periods of 0.5 (i.e. 12 hours), $c_{p}$ and $b_{b p}$ signals are in anti-phase with Chl-Fluo. Due to this limited productivity, cycles greater than 1 day are not the most impactful of the intra-seasonal variability, while conversely the diurnal signal is well pronounced. Oubelkheir and Sciandra (2008) argued that the diel cycle of $\mathrm{c}_{\mathrm{p}}$, and the particles pool, is strictly influenced by changes in the properties of particles (e.g. size, refractive index, shape and internal structure) and also by external environmental and biological agents, as reported by Binder and Durand (2002). During daytime, phytoplankton cells fix external inorganic carbon into organic molecules determining an increase of their diameter and refractive index (Siegel et al., 1989; Stramski and Reynolds, 1993; Walsh et al., 1995), and as a consequence an increase of scattering and attenuation cross section. This was also confirmed by laboratory experiments on a few phytoplankton species (Stramski et al., 1995; Durand and Olson, 1998; Claustre et al. 2002; Poulin et al., 2018). During night-time, phytoplankton cells divide into smaller cells with lower intra-cellular carbon content, as a result of an uptake of water during division or of a loss due to respiration (Durand and Olson, 1998). Another element to consider on the $\mathrm{c}_{\mathrm{p}}$ diel variation is the relative dynamics of algal and non-algal stocks (i.e. heterotrophs, viruses and detritus) that could vary in relation to the season and trophic regimes. Oubelkheir and Sciandra (2008) showed that the $c_{p}$ is strictly related to heterotrophic particles abundance coupled with phytoplankton cells and associated detritus.

To summarize, through the specific three-month WA, more information about detection and power of these additional sources of variability can be obtained. The mid-term cycles ( $>10$ days) dominate intra-seasonal variability during the winter (period of mixing and bloom), while they are of limited impact in the case of summer which is the period of low biological production and absence of extreme meteorological events (Gernez et al., 2011, Kheireddine et al., 2014) indicating where the diel cycle is the most recurrent and important source of signal. 
a)

)

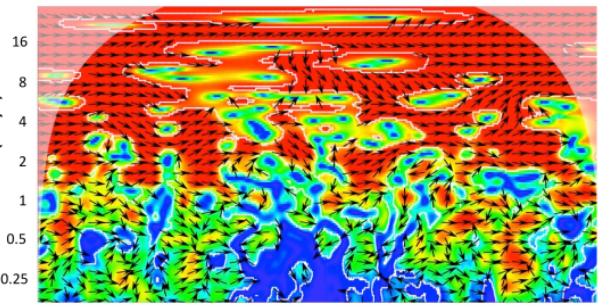

b)

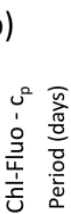

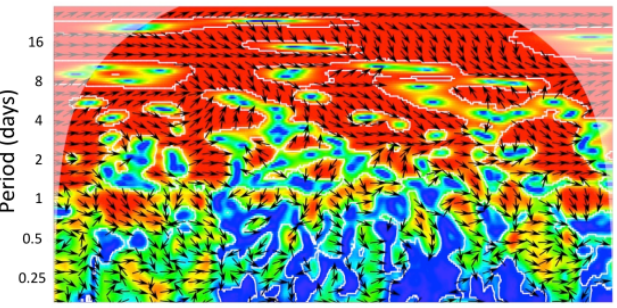

c)

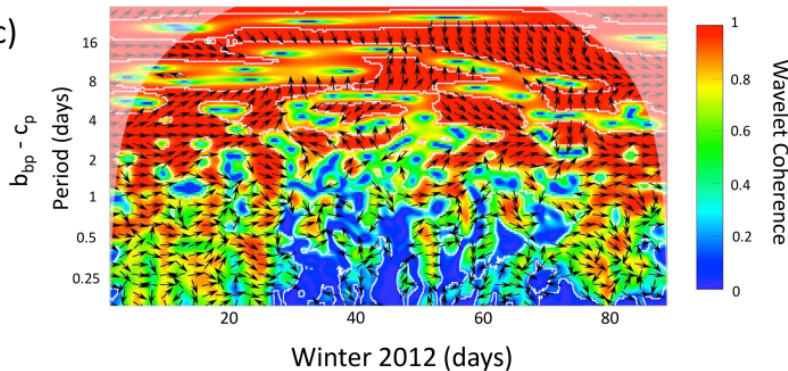

d)

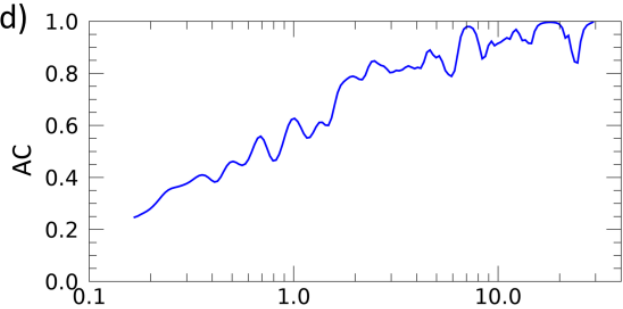

e)

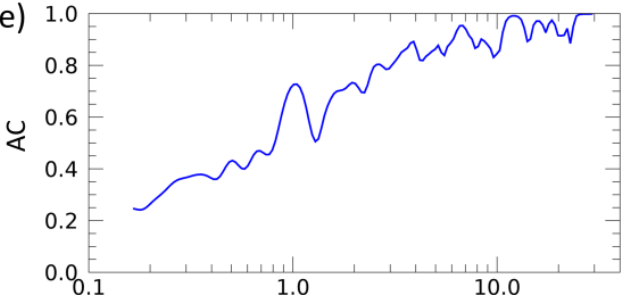

f)

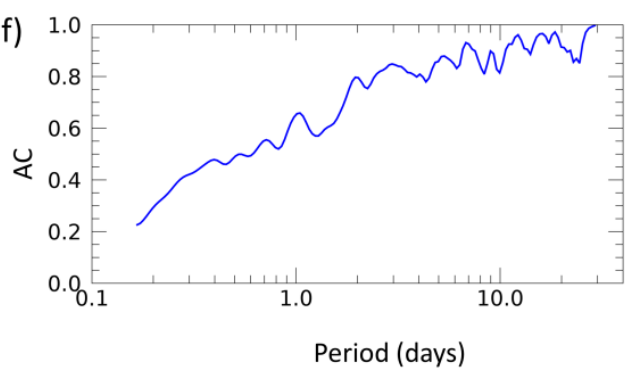

Figure 10: Cross-wavelet coherence spectra between Chl-Fluo and $b_{b p}(a)$, Chl-Fluo and $c_{p}(b)$, and $b_{b p}$ and $c_{p}$ (c) at BOUSSOLE site for the Winter 2012. Color indicates the level of covariability between the time-series (values between 0 and 1); arrows denote the relative phase between the time-series (right: in phase; left: antiphase; up or down: one series leads the other by $90^{\circ}$ ) and significance covariability $(>95 \%$ and thin white contours). Shaded area has not to be considered as it might provide false periodic events (Torrence and Compo, 1998). AC of each parameter are in Panel d-f. In red are highlighted periods where the AC is with low statistical significance (less than 95\%). The significance test is computed following Roesch and Schmidbauer (2014). 
a)

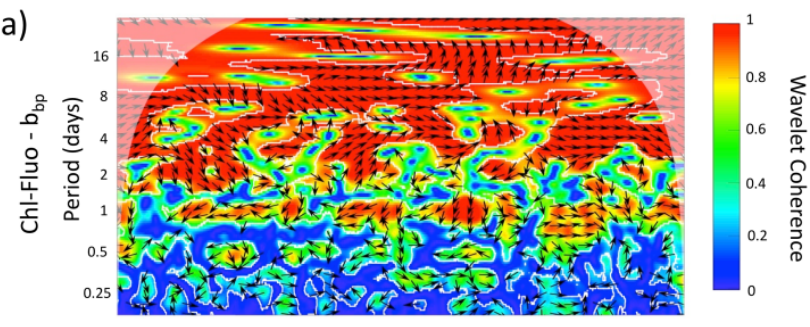

b)

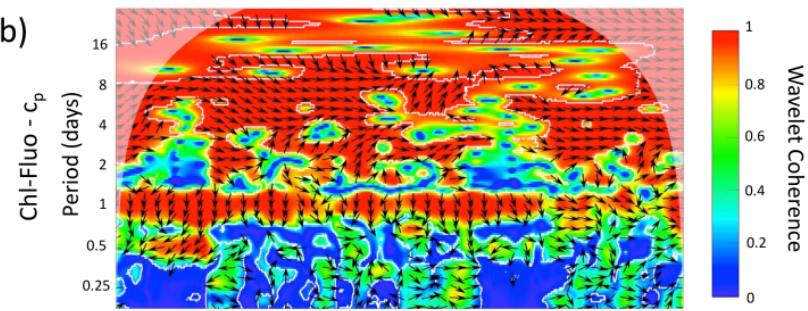

c)

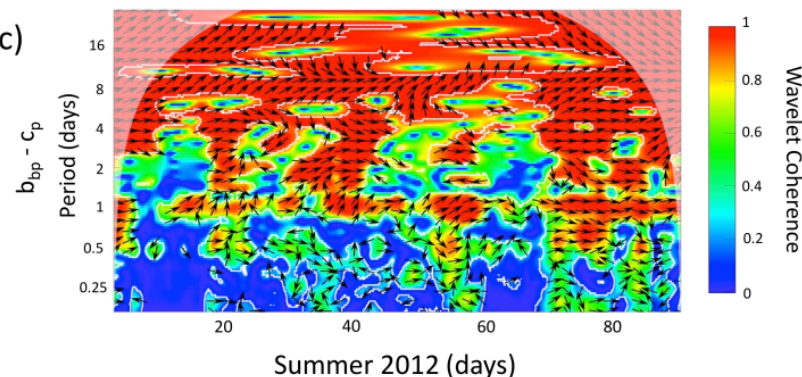

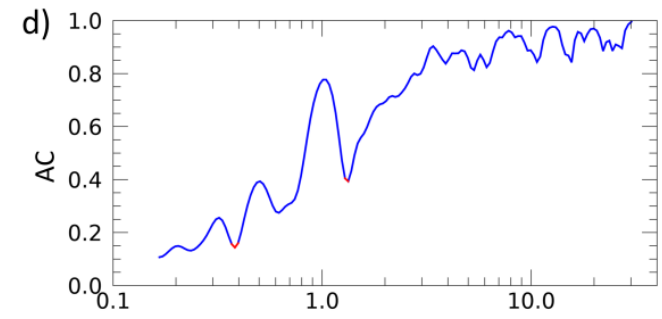

e) 1.0
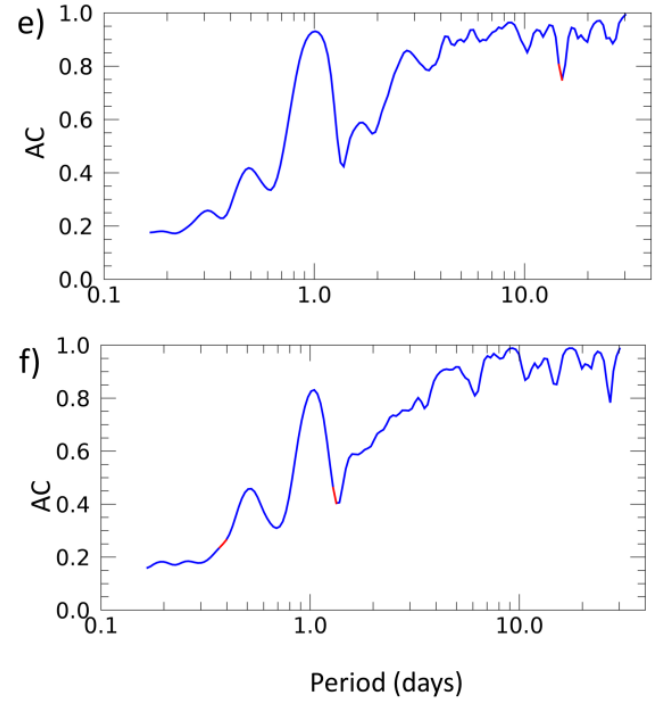

Figure 11: Cross-wavelet coherence spectra between Chl-Fluo and $b_{b p}(a)$, Chl-Fluo and $c_{p}(b)$, and $b_{b p}$ and $c_{p}$ (c) at BOUSSOLE site for the Summer 2012. Color indicates the level of covariability between the timeseries (values between 0 and 1); arrows denote the relative phase between the time-series (right: in phase; left: antiphase; up or down: one series leads the other by $\left.90^{\circ}\right)$ and significance covariability $(>95 \%$ and the thin white contours). Shaded area has not to be considered as it might provide false periodic events (Torrence and Compo, 1998). AC for each parameter are in Panel d-f. In red are highlighted periods where the AC is with low statistical significance (less than 95\%). The significance test is computed following Roesch and Schmidbauer (2014).

\section{Conclusions}

In the last decades, the development of fixed observation sites, such as the BOUSSOLE buoy, as well as remote sensing advancement has helped to study the phenology of phytoplankton and optical properties. Several works have studied temporal variability of bio-optical properties in various oceanic regimes using both field and satellite data (Behrenfeld et al., 2009, Antoine et al., 2011; Gernez et al., 2011; Barnes et al., 2014; Kheireddine et al., 2014; Behrenfeld et al. 2015; Sammartino et al., 2015; Di Cicco et al., 2017). However, most of these phenological studies focus on the annual and seasonal cycles (i.e. long-term cycles), while there is limited literature on the mid- and short-term cycles, and their recurrence, which characterizes the temporal variability of bio-optical properties.

In this study, we have focused on bio-optical properties using, for the first time, a statistical a priori method, as the wavelet analysis (WA) is, on three-year high frequency observations. The main goals are to determine the intra-annual dominant temporal patterns of the bio-optical parameters, the changes of these cycles over time, the characteristics and recurring strength at those periods and to define the temporal relationship between the cycles of the bio-optical properties.

The WA applied here reveals a persistent annual cycle for Chl-Fluo which explains the largest amount of its variability. On the other hand, and unexpectedly, the 6-month cycle is the most 
important and dominant temporal pattern of the $b_{b p}$ and $c_{p}$ time-series, with respect to Chl-Fluo, which accounts for half of the variability in respect to the annual cycle. Together with 6-month, the 4-month cycle is the third source of variability for all the parameters with different strengths. It has a particular recurrence and magnitude in the case of $b_{b p}$, with respect to Chl-Fluo and $c_{p}$ and intraseasonal variability is driven by mid- and short-terms cycles. During the winter (season of mixing), the mid-term cycles ( $>10$ days) are the most important. Episodic bloom events can determine these cycles, as viewed in the case of bio-optical coefficients, and as also found by Winder et al. (2010). During summer, the diel cycle is the most important and the main source of variability, especially for $\mathrm{c}_{\mathrm{p}}$ and Chl-Fluo. Considering the entire time-series, at diel scale, the coherence between spectra of bio-optical coefficients diminishes in respect to annual and seasonal cycles although remaining high. Chl-Fluo $-c_{p}$ and $b_{b p}-c_{p}$ periodicities have a strong temporal correlation in respect to ChlFluo- $b_{b p}$. At diurnal scale, Chl-Fluo depends specifically on intra-cellular and physiological processes in relation to physical forcing, and on phytoplankton cells abundance. The $\mathrm{c}_{\mathrm{p}}$ at the same scale has its own temporal pattern: in summer, $\mathrm{c}_{\mathrm{p}}$ is driven mostly by heterotrophic bacteria coupled with low phytoplankton abundances, while in winter, $\mathrm{c}_{\mathrm{p}}$ is more associated with phytoplankton particles (Oubelkheir et al. 2005, Oubelkheir and Sciandra, 2008). In the case of $b_{\mathrm{bp}}$, the correlation between the periodicities of Chl-Fluo is lower with respect to $c_{p}$ because the $b_{b p}$ is influenced more by small particles (Stramski et al., 2004; Kheireddine et al., 2014). In such a context, the recent findings of Organelli et al. (2018) open challenges in understanding the complexity of marine particles structure as sources of variability of the open-ocean $b_{b p}$ signal that have to be addressed in the next future in order to better constraint the use of $b_{b p}$ observations for investigating the biological carbon pump and phytoplankton phenology studies. This work thus highlights the need to develop in situ technologies as well as new satellite sensors at higher temporal resolutions (e.g. geostationary satellite) for biogeochemical/bio-optical measurements that have been widely recognized as a priority in the optical and oceanographic community. Indeed, high frequency observations could help to study, both in space and time, these mid- and low-term cycles, poorly known, that currently are not taken into account in the ocean color algorithms despite dominating the bio-optical variability at reduced time-series length (i.e. within the season). Lastly, as it is demonstrated here, the importance of the use of WA as a powerful instrument for studying both long or short time-series of bio-optical parameters and their relationships in oceanography (Winder et al., 2010, Damarcq et al. 2012, Ampe et al., 2014, Corredor-Acosta et al., 2015, Carey et al. 2016, Sala et al., 2018).

\section{Acknowledgments}

M. Bellacicco was supported by a postdoctoral fellowship from the Centre Nationales d'Etudes Spatiales (CNES, France). Now, M. Bellacicco is at the Italian National Agency for New Technologies, Energy and Sustainable Economic Development (ENEA) with a postdoctoral fellowship funded by the ESA. Thanks also to European Space Agency (ESA) and CNES for funding the BOUSSOLE project, and to all the OMTAB staffs for BOUSSOLE maintenance. Data are available at the BOUSSOLE project website: http://www.obsvlfr.fr/Boussole/html/project/introduction.php

Additional thanks to the Dr. J. Pitarch, Dr. S. Constantin, prof. M. Scardi and prof. A. Bellacicco for suggestions on this work. The authors finally wish to thank the R Core Team (http://www.Rproject.org/) for open source software package. 


\section{References}

1. Ampe, E. M., Hestir, E. L., Bresciani, M., Salvadore, E., Brando, V. E., Dekker, A., ... \& Batelaan, O. (2014). A wavelet approach for estimating chlorophyll-a from inland waters with reflectance spectroscopy. IEEE Geoscience and Remote Sensing Letters, 11(1), 89-93.

2. Antoine, D., et al. (2006), BOUSSOLE: A joint CNRS-INSU, ESA, CNES and NASA Ocean Color Calibration And Validation Activity, NASA Technical memorandum N2006 - 214147, $61 \mathrm{pp}$.

3. Antoine, D., F. D’Ortenzio, S. B. Hooker, G. Becu, B. Gentili, D. Tailliez, and A. J. Scott (2008a), Assessment of uncertainty in the ocean reflectance determined by three satellite ocean color sensors (MERIS, SeaWiFS and MODIS-A) at an offshore site in the Mediterranean Sea (BOUSSOLE project), J. Geophys. Res., 113, C07013, doi:10.1029/2007JC004472.

4. Antoine, D., P. Guevel, J. F. Deste, G. Becu, F. Louis, A. J. Scott, and P. Bardey (2008b), The "BOUSSOLE" buoy-A new transparent-to-swell taut mooring dedicated to marine optics: Design, tests, and performance at sea, J. Atmos. Oceanic Technol., 25, 968-989, doi:10.1175/ $2007 \mathrm{j}$ techo563.1

5. Antoine, D., Siegel, D. A., Kostadinov, T., Maritorena, S., Nelson, N. B., Gentili, B., ... \& Guillocheau, N. (2011). Variability in optical particle backscattering in contrasting bio-optical oceanic regimes. Limnology and Oceanography, 56(3), 955-973.

6. Barbieux, M., Uitz, J., Bricaud, A., Organelli, E., Poteau, A., Schmechtig, C., ... \& D'Ortenzio, F. (2018). Assessing the Variability in the Relationship Between the Particulate Backscattering Coefficient and the Chlorophyll a Concentration From a Global Biogeochemical-Argo Database. Journal of Geophysical Research: Oceans, 123(2), 1229-1250.

7. Barnes, M., \& Antoine, D. (2014). Proxies of community production derived from the diel variability of particulate attenuation and backscattering coefficients in the northwest Mediterranean Sea. Limnol. Oceanogr, 59(6), 2133-2149.

8. Behrenfeld, M. J., \& Boss, E. (2003). The beam attenuation to chlorophyll ratio: an optical index of phytoplankton physiology in the surface ocean?. Deep Sea Research Part I: Oceanographic Research Papers, 50(12), 1537-1549.

9. Behrenfeld, M. J., Boss, E., Siegel, D. A., \& Shea, D. M. (2005). Carbon-based ocean productivity and phytoplankton physiology from space. Global biogeochemical cycles, 19(1).

10. Behrenfeld, M. J., \& Boss, E. (2006). Beam attenuation and chlorophyll concentration as alternative optical indices of phytoplankton biomass. Journal of Marine Research, 64(3), 431451.

11. Behrenfeld, M. J., Westberry, T. K., Boss, E. S., O'Malley, R. T., Siegel, D. A., Wiggert, J. D., ... \& Moore, J. K. (2009). Satellite-detected fluorescence reveals global physiology of ocean phytoplankton. Biogeosciences, 6(5).

12. Behrenfeld, M. J. (2010). Abandoning Sverdrup's critical depth hypothesis on phytoplankton blooms. Ecology, 91(4), 977-989.

13. Behrenfeld, M. J., O’Malley, R. T., Boss, E. S., Westberry, T. K., Graff, J. R., Halsey, K. H., ... \& Brown, M. B. (2016). Revaluating ocean warming impacts on global phytoplankton. Nature Climate Change, 6(3), 323-330.

14. Bellacicco, M., Volpe, G., Colella, S., Pitarch, J., \& Santoleri, R. (2016). Influence of photoacclimation on the phytoplankton seasonal cycle in the Mediterranean Sea as seen by satellite. Remote Sensing of Environment, 184, 595-604.

15. Bellacicco, M., Volpe, G., Briggs, N., Brando, V., Pitarch, J., Landolfi, A., Colella, S., Marullo, S. and Santoleri, R. (2018). Global Distribution of Non-Algal Particles From Ocean Color Data and Implications for Phytoplankton Biomass Detection. Geophysical Research Letters, 45(15), 7672-7682.

16. Beckers, J.M.; Rixen, M. EOF calculations and data filling from incomplete oceanographic datasets. J. Atmos. Ocean. Technol. 2003, 20, 1839-1856. 
17. Binder, B. J., \& Durand, M. D. (2002). Diel cycles in surface waters of the equatorial Pacific. Deep Sea Research Part II: Topical Studies in Oceanography, 49(13), 2601-2617.

18. Bode, A., Estévez, M. G., Varela, M., \& Vilar, J. A. (2015). Annual trend patterns of phytoplankton species abundance belie homogeneous taxonomical group responses to climate in the NE Atlantic upwelling. Marine environmental research, 110, 81-91.

19. Bosc, E., Bricaud, A., \& Antoine, D. (2004). Seasonal and interannual variability in algal biomass and primary production in the Mediterranean Sea, as derived from 4 years of SeaWiFS observations. Global Biogeochemical Cycles, 18(1).

20. Boss, E., and W. S. Pegau (2001), Relationship of light scattering at an angle in the backward direction to the backscattering coefficient, Appl. Opt., 40, 5503-5507, doi:10.1364/ao.40.005503.

21. Brewin, R. J., Dall'Olmo, G., Sathyendranath, S., \& Hardman-Mountford, N. J. (2012). Particle backscattering as a function of chlorophyll and phytoplankton size structure in the openocean. Optics express, 20(16), 17632-17652.

22. Bricaud, A., Morel, A., \& Prieur, L. (1981). Absorption by dissolved organic matter of the sea (yellow substance) in the UV and visible domains. Limnology and oceanography, 26(1), 43-53

23. Carey, C. C., Hanson, P. C., Lathrop, R. C., \& St. Amand, A. L. (2016). Using wavelet analyses to examine variability in phytoplankton seasonal succession and annual periodicity. Journal of Plankton Research, 38(1), 27-40

24. Cazelles, B., Chavez, M., Berteaux, D., Ménard, F., Vik, J. O., Jenouvrier, S., \& Stenseth, N. C. (2008). Wavelet analysis of ecological time series. Oecologia, 156(2), 287-304.

25. Chatfield JR (1989) The analysis of time series: an introduction. Chapman \& Hall, London

26. Claustre, H., A. Morel, M. Babin, C. Cailliau, D. Marie, J. C. Marty, D. Tailliez, and D. Vaulot (1999), Variability in particle attenuation and chlorophyll fluorescence in the tropical Pacific: Scales, patterns, and biogeochemical implications, J. Geophys. Res., 104, 3401-3422, doi: 10.1029/98JC01334.

27. Claustre, H., Bricaud, A., Babin, M., Bruyant, F., Guillou, L., Le Gall, F., ... \& Partensky, F. (2002). Diel variations in Prochlorococcus optical properties. Limnology and Oceanography, 47(6), 1637-1647.

28. Cleland, E. E., Chuine, I., Menzel, A., Mooney, H. A. \& Schwartz, M. D. (2007). Shifting plant phenology in response to climate change. Trends Ecol. Evol. 22, 357-365.

29. Corredor-Acosta, A., Morales, C. E., Hormazabal, S., Andrade, I., \& Correa-Ramirez, M. A. (2015). Phytoplankton phenology in the coastal upwelling region off central-southern Chile $\left(35^{\circ}\right.$ $\left.\mathrm{S}-38^{\circ} \mathrm{S}\right)$ : Time-space variability, coupling to environmental factors, and sources of uncertainty in the estimates. Journal of Geophysical Research: Oceans, 120(2), 813-831.

30. Dall'Olmo, G., Westberry, T. K., Behrenfeld, M. J., Boss, E., \& Slade, W. H. (2009). Significant contribution of large particles to optical backscattering in the open ocean. Biogeosciences, 6(6), 947-967.

31. Dall'Olmo, G., Boss, E., Behrenfeld, M. J., \& Westberry, T. K. (2012). Particulate optical scattering coefficients along an Atlantic Meridional Transect. Optics express, 20(19), 2153221551.Damarcq, H., Reygondeau, G., Alvain, S., \& Vantrepotte, V. (2012). Monitoring marine phytoplankton seasonality from space. Remote Sensing of Environment, 117, 211-222.

32. Daubechies, I. (1992). Ten lectures on wavelets. Society for industrial and applied mathematics.

33. D'Ortenzio, F., Iudicone, D., de Boyer Montegut, C., Testor, P., Antoine, D., Marullo, S., ... \& Madec, G. (2005). Seasonal variability of the mixed layer depth in the Mediterranean Sea as derived from in situ profiles. Geophysical Research Letters, 32(12).

34. D'Ortenzio, F., Lavigne, H., Besson, F., Claustre, H., Coppola, L., Garcia, N., ... \& Morin, P. (2014). Observing mixed layer depth, nitrate and chlorophyll concentrations in the northwestern Mediterranean: A combined satellite and NO3 profiling floats experiment. Geophysical Research Letters, 41(18), 6443-6451 
35. Durand, M. D., \& Olson, R. J. (1998). Diel patterns in optical properties of the chlorophyte Nannochloris sp.: Relating individual-cell to bulk measurements. Limnology and Oceanography, 43(6), 1107-1118.

36. García-Reyes, M., Sydeman, W. J., Black, B. A., Rykaczewski, R. R., Schoeman, D. S., Thompson, S. A., \& Bograd, S. J. (2013). Relative influence of oceanic and terrestrial pressure systems in driving upwelling-favorable winds. Geophysical Research Letters, 40(19), 53115315.

37. Gernez, P., Antoine, D., \& Huot, Y. (2011). Diel cycles of the particulate beam attenuation coefficient under varying trophic conditions in the northwestern Mediterranean Sea: Observations and modeling. Limnology and Oceanography, 56(1), 17-36.

38. Ghil, M., Allen, M. R., Dettinger, M. D., Ide, K., Kondrashov, D., Mann, M. E., ... \& Yiou, P. (2002). Advanced spectral methods for climatic time series. Reviews of geophysics, 40(1)

39. Halsey, K. H., \& Jones, B. M. (2015). Phytoplankton strategies for photosynthetic energy allocation. Annual review of marine science, 7, 265-297.

40. Huot, Y., Babin, M., Bruyant, F., Grob, C., Twardowski, M., Claustre, H., 2007. Relationship between photosynthetic parameters and different proxies of phytoplankton biomass in the subtropical ocean. Biogeosciences, 4 (5), 853-868.

41. Huot, Y., Morel, A., Twardowski, M.S., Stramski, D., Reynolds, R.A., 2008. Particle optical backscattering along a chlorophyll gradient in the upper layer of the eastern South Pacific Ocean. Biogeosciences, 5 (2), 495-507.

42. Ji, R., Edwards, M., Mackas, D. L., Runge, J. A., \& Thomas, A. C. (2010). Marine plankton phenology and life history in a changing climate: current research and future directions. Journal of plankton research, 32(10), 1355-1368.

43. Kheireddine, M., \& Antoine, D. (2014). Diel variability of the beam attenuation and backscattering coefficients in the northwestern Mediterranean Sea (BOUSSOLE site). Journal of Geophysical Research: Oceans, 119(8), 5465-5482

44. Kondrashov, D., Feliks, Y., \& Ghil, M. (2005). Oscillatory modes of extended Nile River records (AD 622-1922). Geophysical research letters, 32(10).

45. Kondrashov, D., \& Ghil, M. (2006). Spatio-temporal filling of missing points in geophysical data sets. Nonlinear Processes in Geophysics, 13(2), 151-159.

46. Kondrashov, D., Shprits, Y., \& Ghil, M. (2010). Gap filling of solar wind data by singular spectrum analysis. Geophysical research letters, 37(15)Lavigne, H., D'Ortenzio, F., Migon, C., Claustre, H., Testor, P., d'Alcalà, M. R., ... \& Prieur, L. (2013). Enhancing the comprehension of mixed layer depth control on the Mediterranean phytoplankton phenology. Journal of Geophysical Research: Oceans, 118(7), 3416-3430.

47. Lau KM, Weng H (1995). Climatic signal detection using wavelet transform: how to make a time series sing. Bull Am Meteorol Soc 76:2391-2402

48. Lee, Z. P., K. L. Carder, and R. A. Arnone (2002), Deriving inherent optical properties from water color: A multiband quasi-analytical algorithm for optically deep waters, Appl. Opt., 41, 5755-5772, doi:10.1364/ao.41.005755.

49. Loisel, H., Bosc, E., Stramski, D., Oubelkheir, K., \& Deschamps, P. Y. (2001). Seasonal variability of the backscattering coefficient in the Mediterranean Sea based on satellite SeaWiFS imagery. Geophysical Research Letters, 28(22), 4203-4206.

50. Loisel, H., Vantrepotte, V., Norkvist, K., Meriaux, X., Kheireddine, M., Ras, J., ... \& Mauriac, R. (2011). Characterization of the bio-optical anomaly and diurnal variability of particulate matter, as seen from scattering and backscattering coefficients, in ultra-oligotrophic eddies of the Mediterranean Sea. Biogeosciences, 8(11), 3295-3317.

51. Maffione, R. A., and D. R. Dana (1997), Instruments and methods for measuring the backwardscattering coefficient of ocean waters, Appl. Opt., 36, 6057-6067, doi:10.1364/ao.36.006057. 
52. Martinez-Vicente, V., Dall'Olmo, G., Tarran, G., Boss, E., \& Sathyendranath, S. (2013). Optical backscattering is correlated with phytoplankton carbon across the Atlantic Ocean. Geophysical Research Letters, 40(6), 1154-1158.

53. Mayot, N., D'Ortenzio, F., d'Alcala, M. R., Lavigne, H., \& Claustre, H. (2016). Interannual variability of the Mediterranean trophic regimes from ocean color satellites. Biogeosciences, 13(6), 1901-1917.

54. Mayot, N., D'Ortenzio, F., Uitz, J., Gentili, B., Ras, J., Vellucci, V., ... \& Claustre, H. (2017). Influence of the phytoplankton community structure on the spring and annual primary production in the North-Western Mediterranean Sea. Journal of Geophysical Research: Oceans.

55. Mignot, A., Claustre, H., Uitz, J., Poteau, A., D'Ortenzio, F., \& Xing, X. (2014). Understanding the seasonal dynamics of phytoplankton biomass and the deep chlorophyll maximum in oligotrophic environments: A Bio-Argo float investigation. Global Biogeochemical Cycles, 28(8), 856-876

56. Mignot, A., Ferrari, R., \& Claustre, H. (2018). Floats with bio-optical sensors reveal what processes trigger the North Atlantic bloom. Nature Communications, 9(1), 190.

57. Millot, C. (1999). Circulation in the western Mediterranean Sea. Journal of marine systems, 20(1), 423-442.

58. Monteiro, P., Gregor, L., Lévy, M., Maenner, S., Sabine, C. L., \& Swart, S. (2015). Intraseasonal variability linked to sampling alias in air-sea $\mathrm{CO} 2$ fluxes in the Southern Ocean. Geophysical Research Letters, 42(20), 8507-8514.

59. Morel, A., and Y.-H. Ahn (1991), Optics of heterotrophic nanoflagellates and ciliates: A tentative assessment of their scattering role in oceanic waters compared to those of bacterial and algal cells, Journal of Marine Research, 49, 177-202.

60. Morlet J., Arens G., Fourgeau E., and Giard D., 1982. Wave propagation and sampling theory Part I: complex signal and scattering in multilayered media. Geophysics, 47, 203-221.

61. Morlet J., Arens G., Fourgeau E., and Giard D., 1982. Wave propagation and sampling theory Part II: sampling theory and complex waves. Geophysics, 47, 222-236.

62. Morren C (1849a) Le Globe, le Temps et la Vie. Bulletins de l'Académie royale des Sciences, des Lettres et des Beaux-Arts de Belgique, XVI(2):660-684

63. Neukermans, G., Loisel, H., Mériaux, X., Astoreca, R., \& McKee, D. (2012). In situ variability of mass-specific beam attenuation and backscattering of marine particles with respect to particle size, density, and composition. Limnology and Oceanography, 57(1), 124-144.

64. Neveux, J.; Dupouy, C.; Blanchot, J.; Le Bouteiller, A.; Landry, M.R.; Brown, S.L. Diel dynamics of chlorophylls in high-nutrient, low-chlorophyll waters of the equatorial Pacific $\left(180^{\circ}\right)$. (2003) Interactions of growth, grazing, physiological responses, and mixing. J. Geophys. Res. Oceans, 108, doi:10.1029/2000JC000747.

65. Nezlin, N. P., Afanasyev, Y. D., Ginzburg, A. I., \& Kostianoy, A. G. (2002). Remotely sensed studies of phytoplankton dynamics under physical forcing in different ocean regions. Advances in Space Research, 29(1), 99-106.

66. Organelli, E., Dall'Olmo, G., Brewin, R. J., Tarran, G. A., Boss, E., \& Bricaud, A. (2018). The open-ocean missing backscattering is in the structural complexity of particles. Nature communications, 9(1), 5439.

67. Oubelkheir, K., Claustre, H., Sciandra, A., \& Babin, M. (2005). Bio-optical and biogeochemical properties of different trophic regimes in oceanic waters. Limnology and oceanography, 50(6), 1795-1809.

68. Oubelkheir, K., \& Sciandra, A. (2008). Diel variations in particle stocks in the oligotrophic waters of the Ionian Sea (Mediterranean). Journal of Marine Systems, 74(1), 364-371.

69. Percival, D. B., \& Walden, A. T. (2000). Wavelet methods for time series analysis, vol. 4 of Cambridge Series in Statistical and Probabilistic Mathematics. 
70. Poulin, C., Antoine, D., \& Huot, Y. (2018). Diurnal variations of the optical properties of phytoplankton in a laboratory experiment and their implication for using inherent optical properties to measure biomass. Optics Express, 26(2), 711-729

71. Roesch, A., \& Schmidbauer, H. (2014). WaveletComp: Computational Wavelet Analysis. R package version 1.0.

72. Sala, I., Navarro, G., Bolado-Penagos, M., Echevarría, F., \& García, C. M. (2018). HighChlorophyll-Area Assessment Based on Remote Sensing Observations: The Case Study of Cape Trafalgar. Remote Sensing, 10(2), 165.

73. Sammartino, M., Di Cicco, A., Marullo, S., \& Santoleri, R. (2015). Spatio-temporal variability of micro-, nano-and pico-phytoplankton in the Mediterranean Sea from satellite ocean colour data of SeaWiFS. Ocean Science, 11(5), 759.

74. Siegel, D. A., T. D. Dickey, L. Washburn, M. K. Hamilton, and B. G. Mitchell (1989), Optical determination of particulate abundance and production variations in the oligotrophic ocean, Deep Sea Res., Part A, 36, 211-222, doi:10.1016/0198-0149(89)90134-9.

75. Siegel, D. A., Behrenfeld, M. J., Maritorena, S., McClain, C. R., Antoine, D., Bailey, S. W., ... \& Eplee Jr, R. E. (2013). Regional to global assessments of phytoplankton dynamics from the SeaWiFS mission. Remote Sensing of Environment, 135, 77-91.

76. Slade, W. H., \& Boss, E. (2015). Spectral attenuation and backscattering as indicators of average particle size. Applied optics, 54(24), 7264-7277.

77. Sosik, H. M. (2008). Characterizing seawater constituents from optical properties. In M. Babin, C. S. Roesler, \& J. J. Cullen (Eds.), Real-time coastal observing systems for ecosystem dynamics and harmful algal blooms (pp. 281-329). Paris, France: UNESCO. (peer reviewed)

78. Stramski, D., and D. A. Kiefer (1991), Light scattering by microorganisms in the open ocean, Prog. Oceanogr., 28, 343-383, doi:10.1016/ 0079-6611(91)90032-h.

79. Stramski, D., and R. A. Reynolds (1993), Diel variations in the optical properties of a marine diatom, Limnology and Oceanography, 38, 1347-1364

80. Stramski, D., Boss, E., Bogucki, D., \& Voss, K. J. (2004). The role of seawater constituents in light backscattering in the ocean. Progress in Oceanography, 61(1), 27-56.

81. Stramski, D., A. Shalapyonok, and R. A. Reynolds (1995), Optical characterisation of the oceanic unicellular cyanobacterium Synechococcus grown under a day-night cycle in natural irradiance, J. Geophys. Res., 100, 13,295-13,307, doi:10.1029/95jc00452.

82. Torrence, C., \& Compo, G. P. (1998). A practical guide to wavelet analysis. Bulletin of the American Meteorological society, 79(1), 61-78.

83. Twardowski, M. S., Boss, E., Macdonald, J. B., Pegau, W. S., Barnard, A. H., \& Zaneveld, J. R. V. (2001). A model for estimating bulk refractive index from the optical backscattering ratio and the implications for understanding particle composition in case I and case II waters. Journal of Geophysical Research: Oceans, 106(C7), 14129-14142

84. Volpe, G., Nardelli, B. B., Cipollini, P., Santoleri, R., \& Robinson, I. S. (2012). Seasonal to interannual phytoplankton response to physical processes in the Mediterranean Sea from satellite observations. Remote Sensing of Environment, 117, 223-235.

85. Walsh, I. D., S. P. Chung, M. J. Richardson, and W. D. Gardner (1995), The diel cycle in the integrated particle load in the equatorial pacific: A comparison with primary production, Deep Sea Res., Part II, 42, 465-477, doi:10.1016/0967-0645(95)00030-t.

86. Winder, M., \& Cloern, J. E. (2010). The annual cycles of phytoplankton biomass. Philosophical Transactions of the Royal Society B: Biological Sciences, 365(1555), 3215-3226.

87. Xing, X., Claustre, H., Boss, E., Roesler, C., Organelli, E., Poteau, A., ... \& D'Ortenzio, F. (2017). Correction of profiles of in-situ chlorophyll fluorometry for the contribution of fluorescence originating from non-algal matter. Limnology and Oceanography: Methods, 15(1), $80-93$

88. Zhang, X. D., and L. B. Hu (2009), Estimating scattering of pure water from density fluctuation of the refractive index, Opt. Express, 17, 1671-1678. 
931 89. Zhang, X. D., L. B. Hu, and M. X. He (2009), Scattering by pure seawater: Effect of salinity, 932 Opt. Express, 17, 5698-5710. 


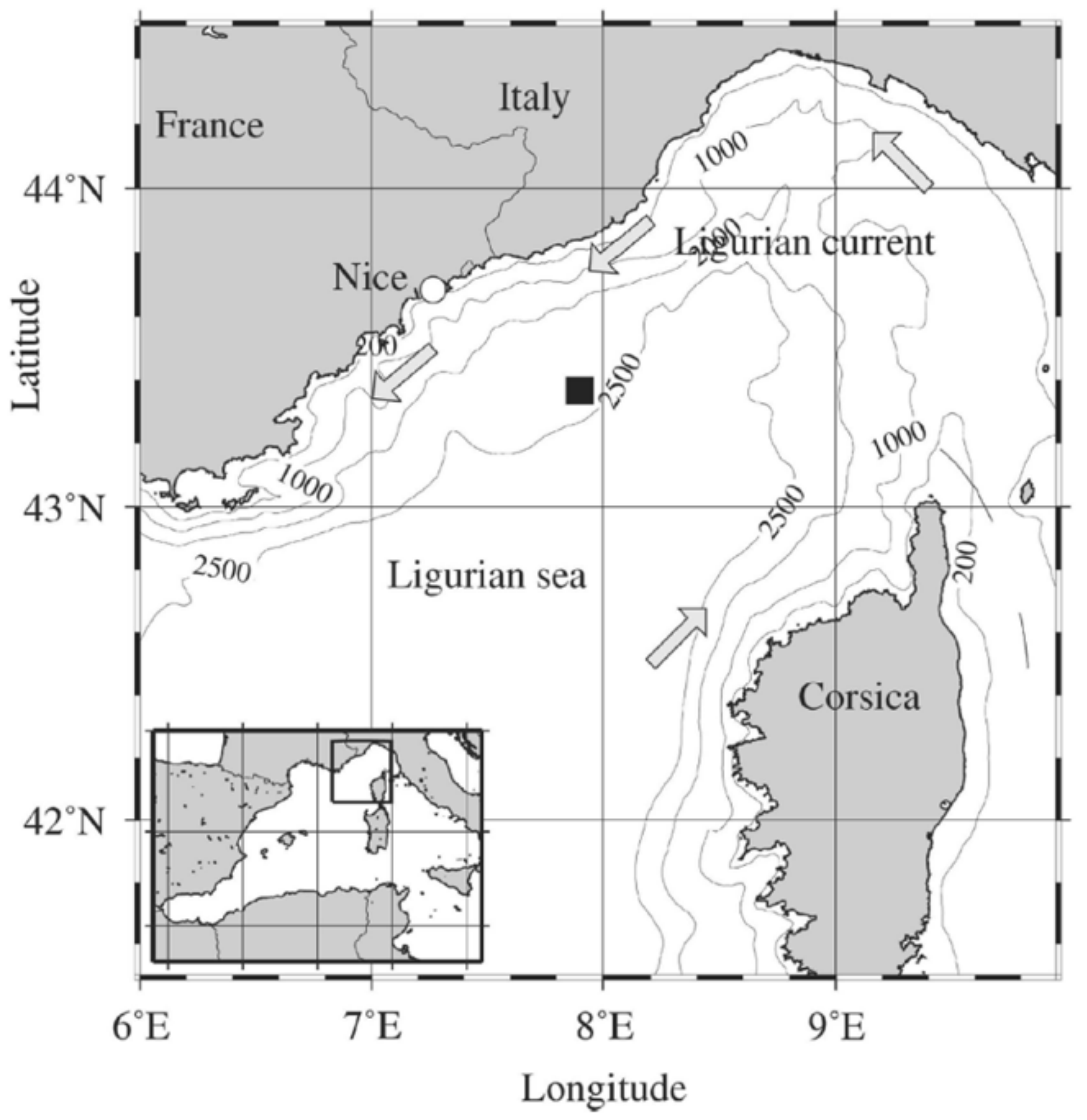



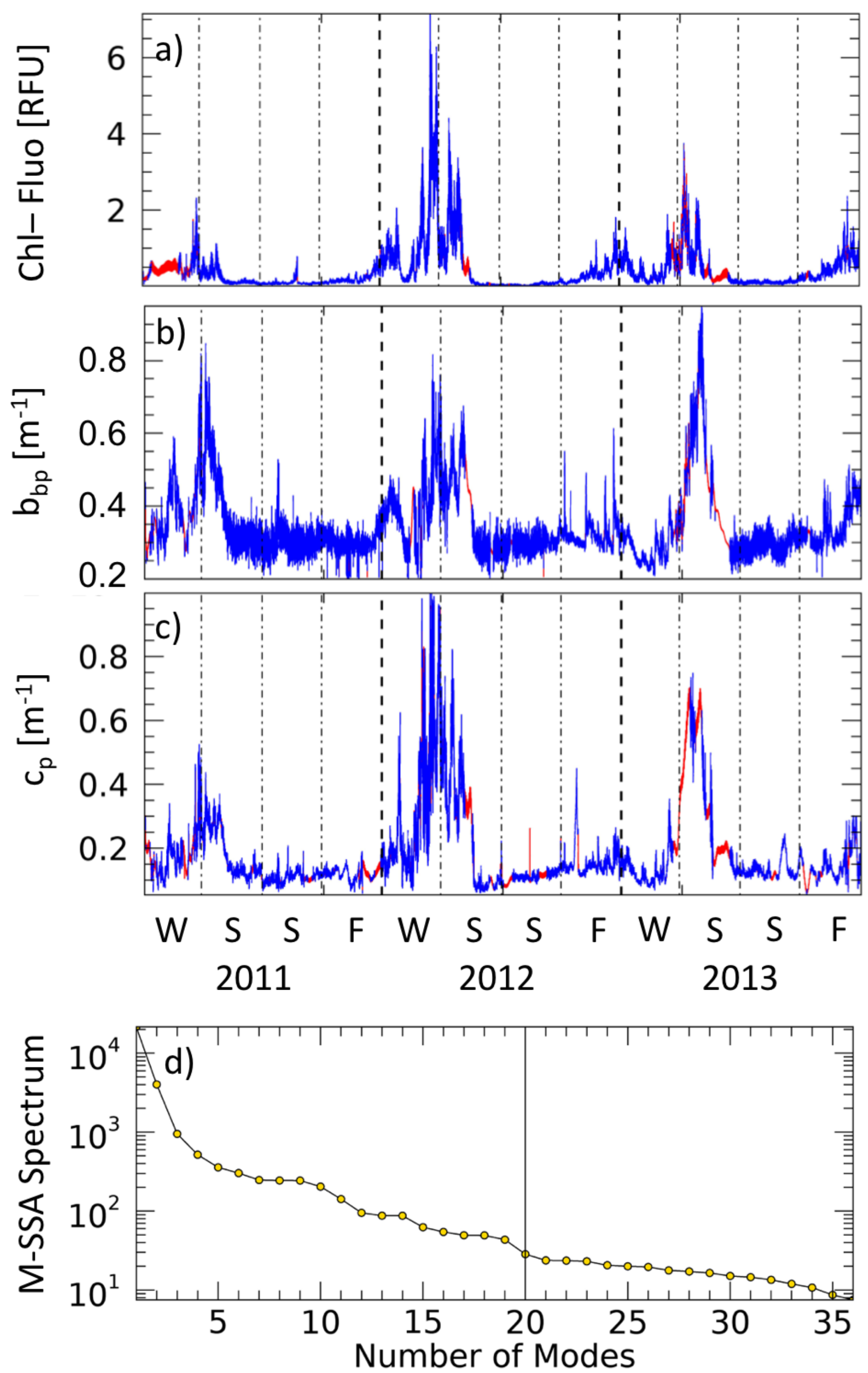
a)

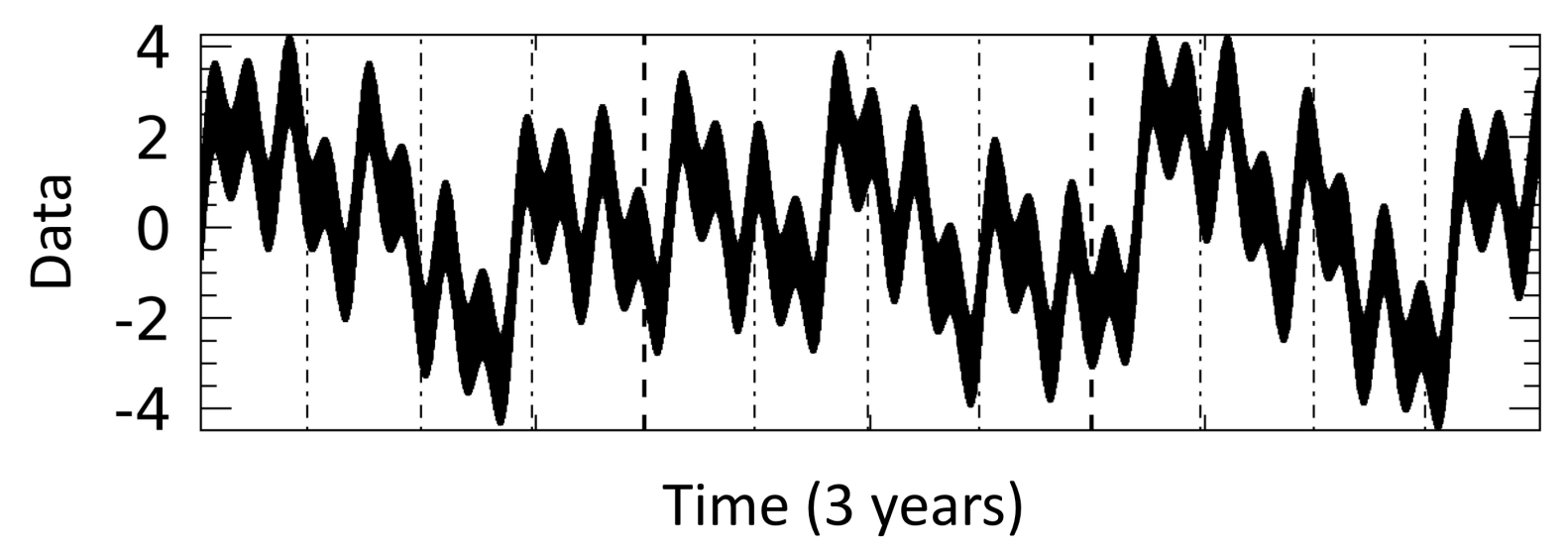

b)

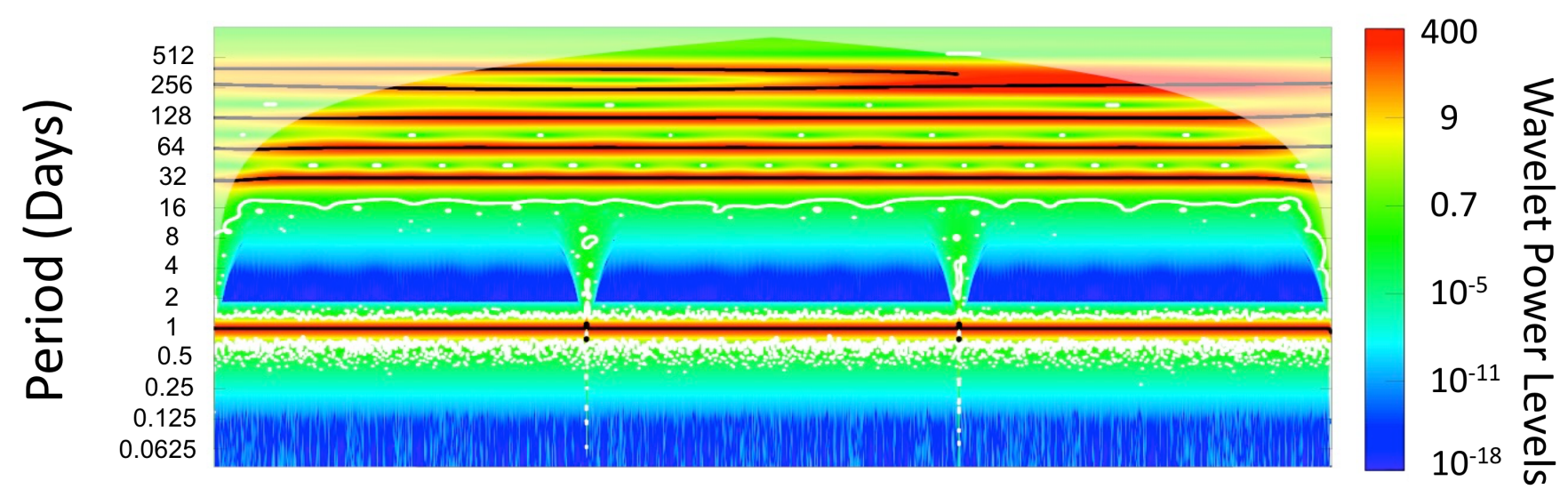

c)

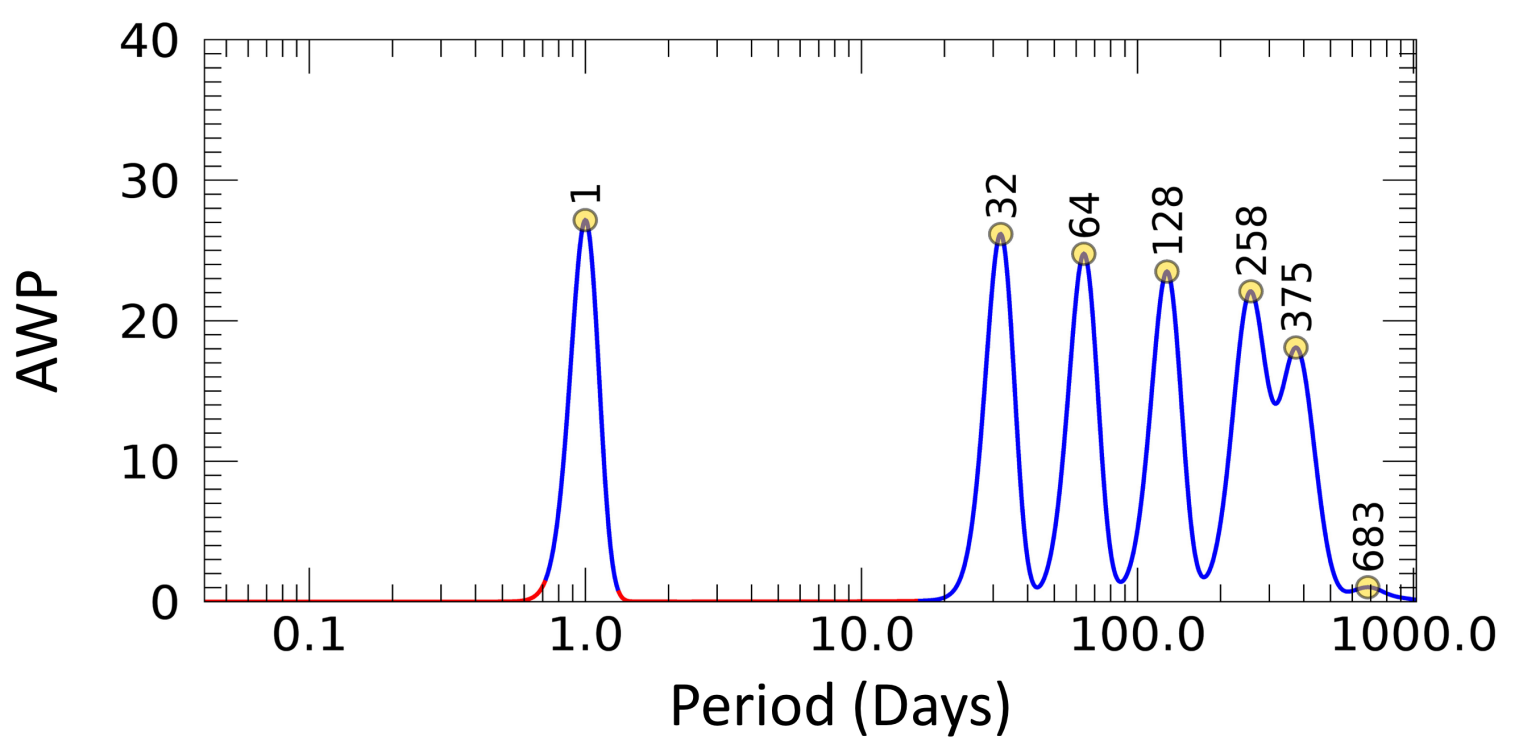



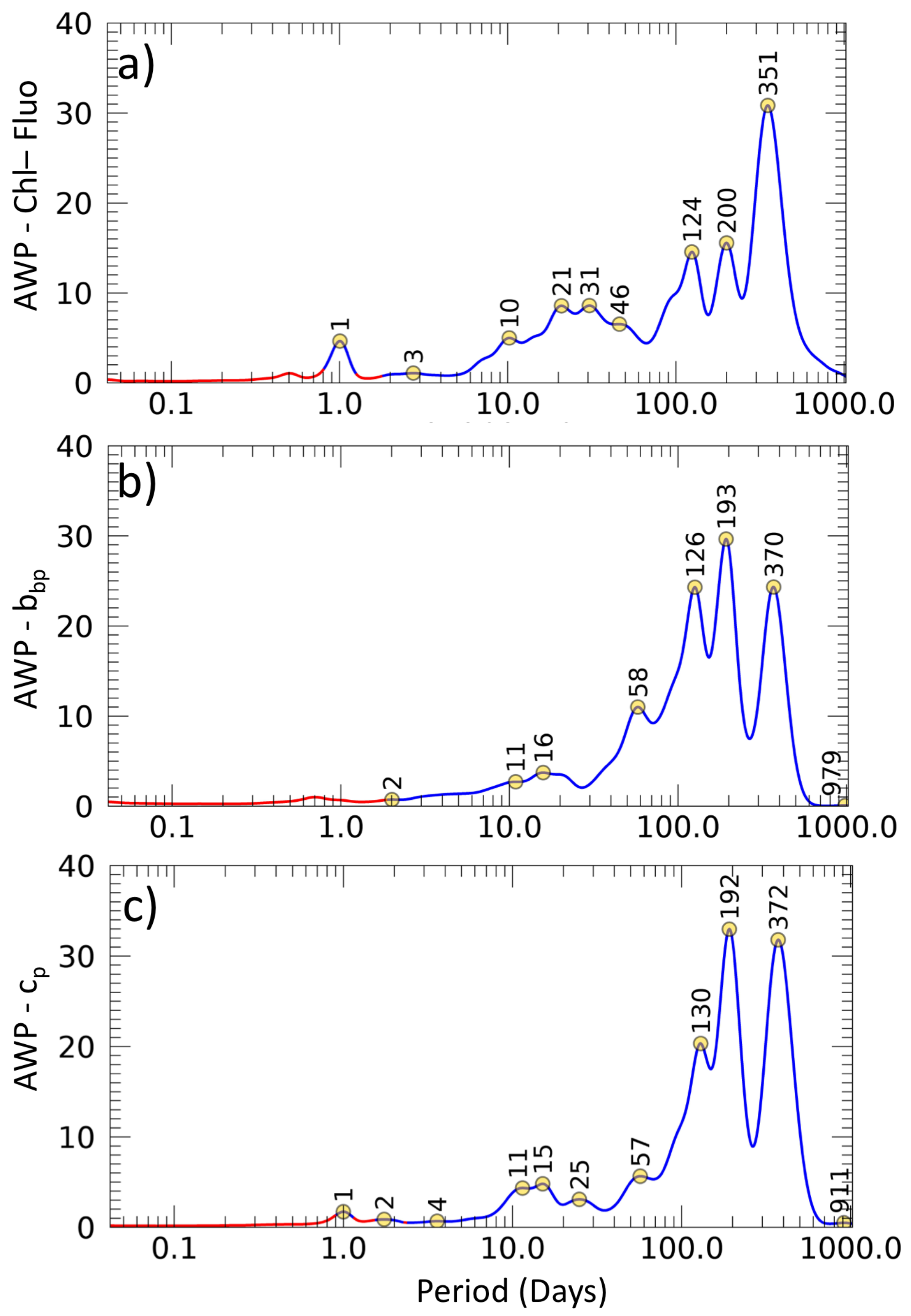

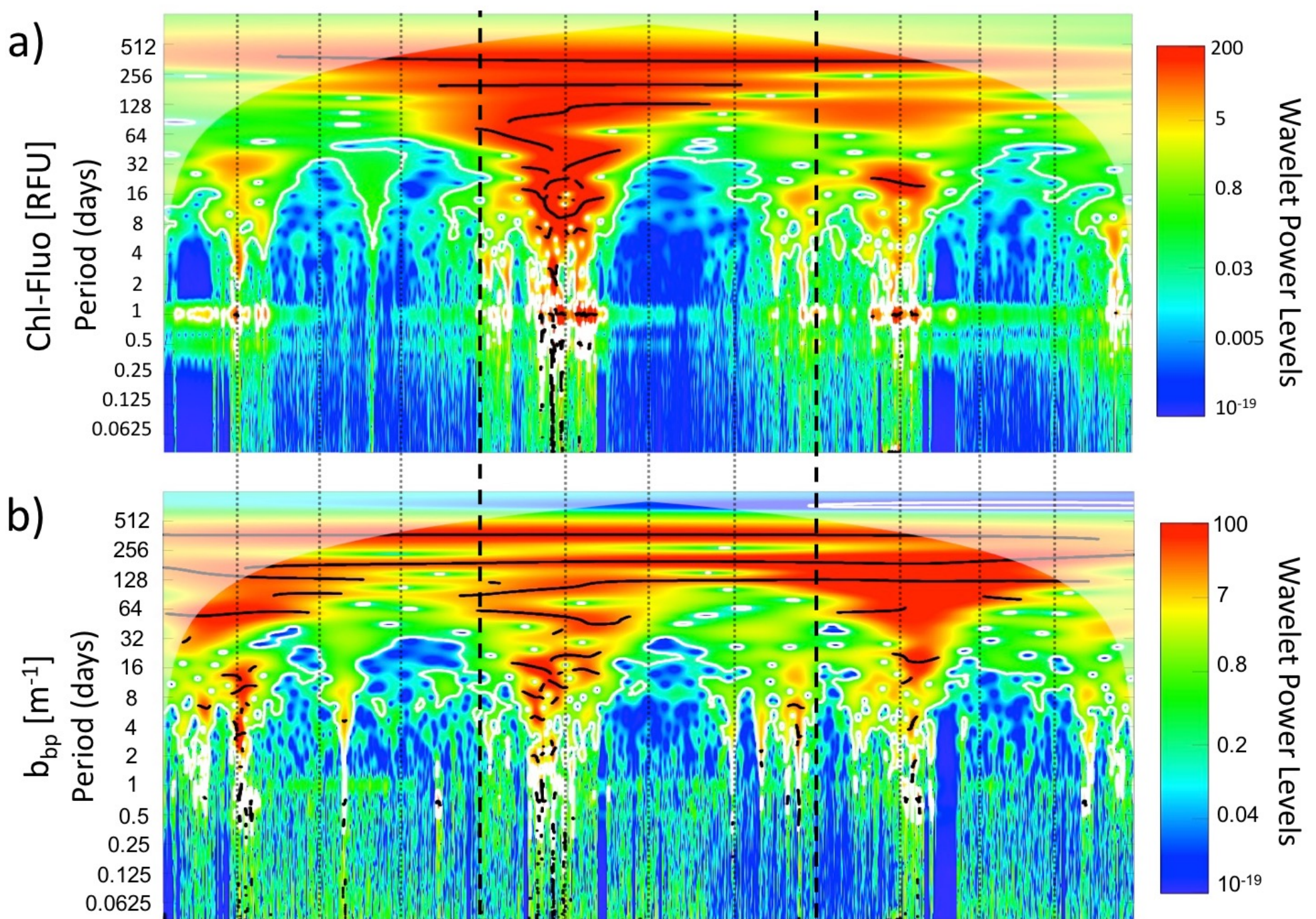

c)

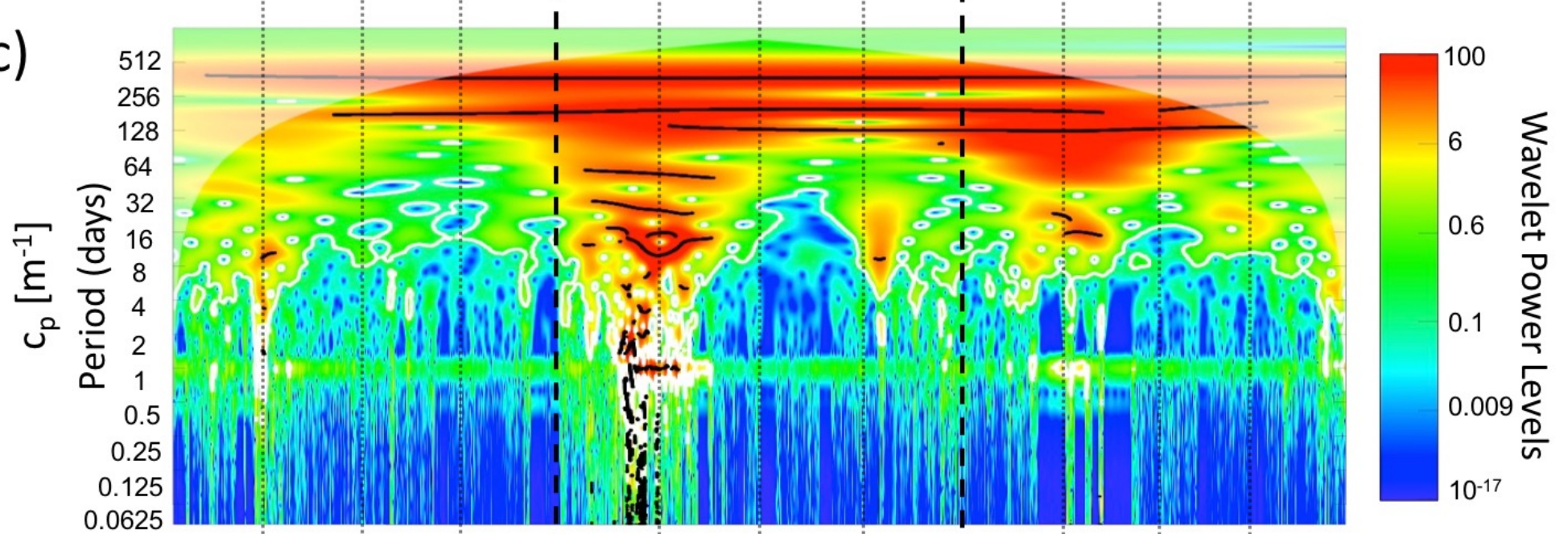

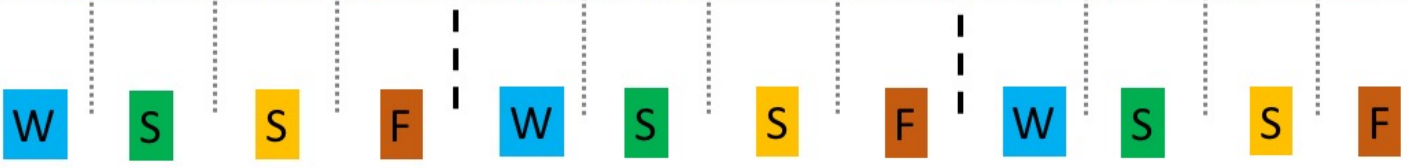
$20112012 \quad 2013$ 


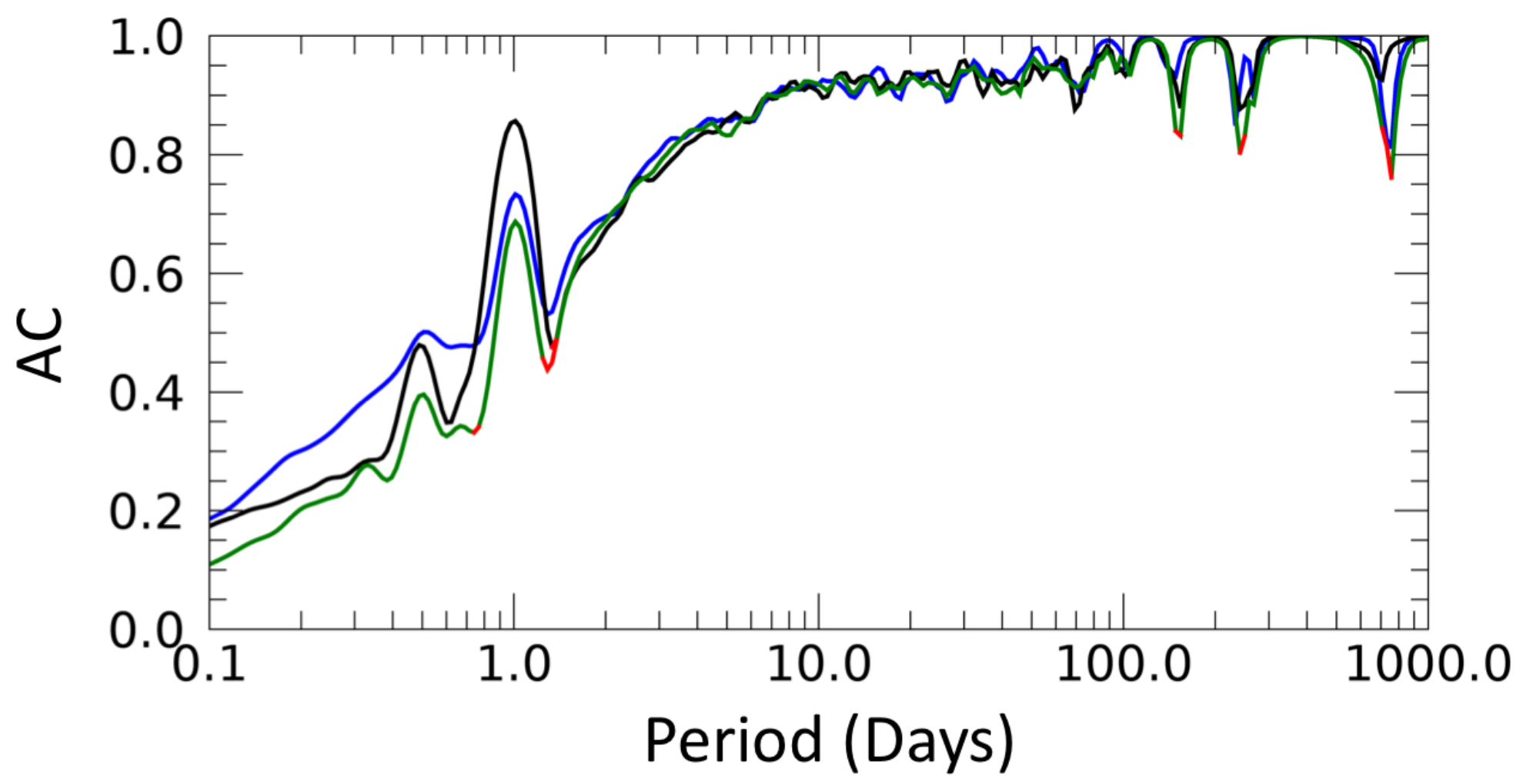



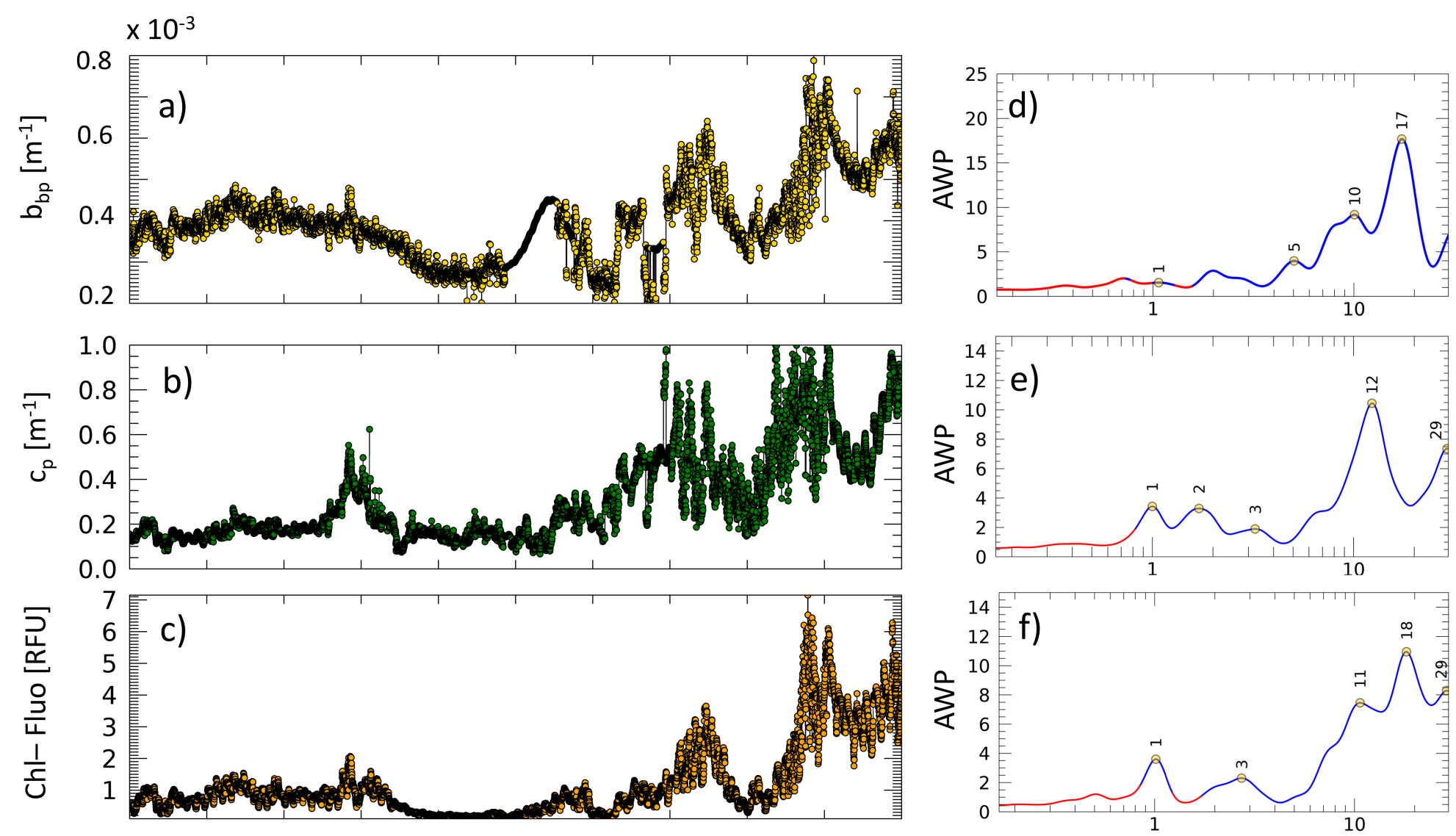

Period (days) 

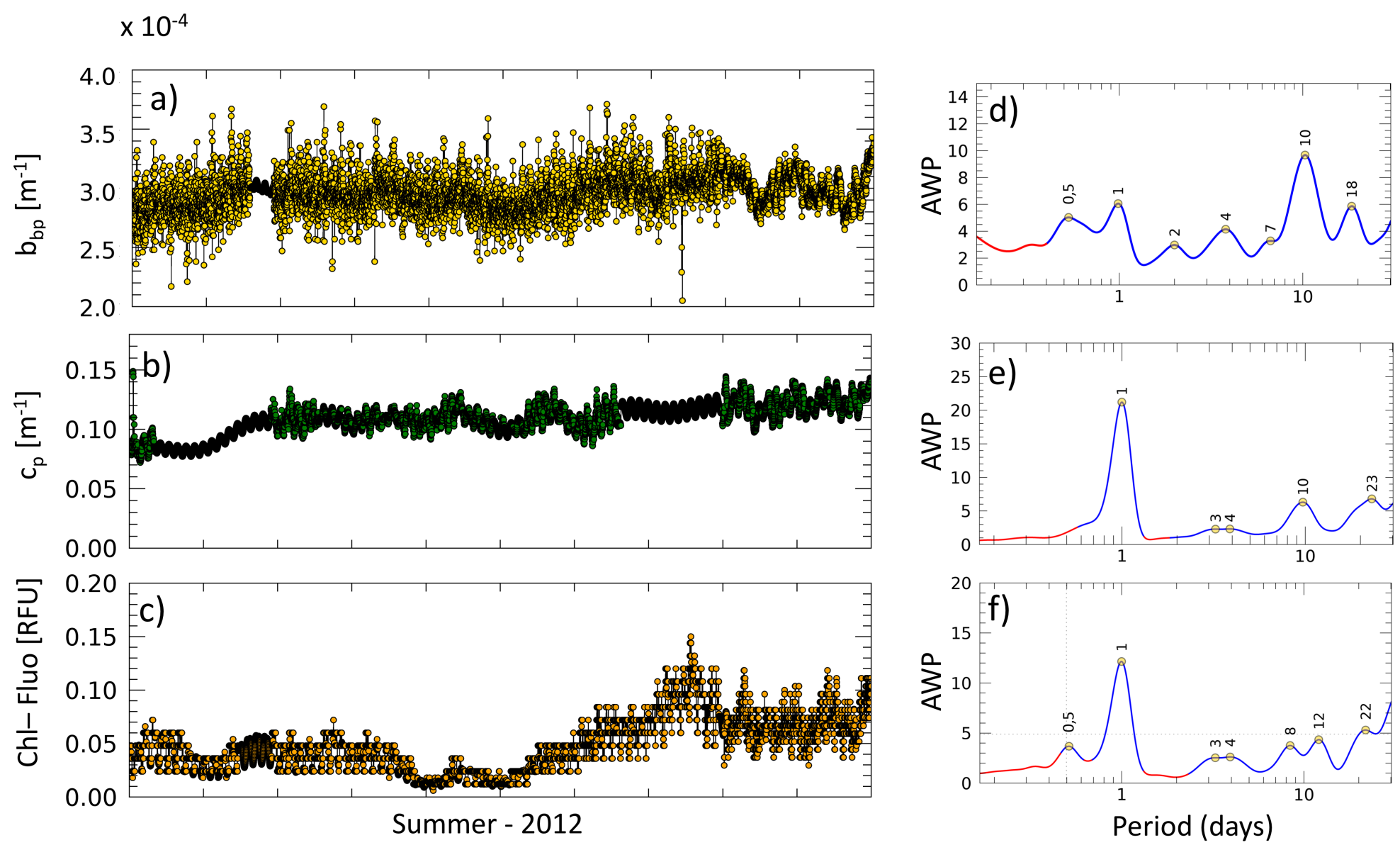

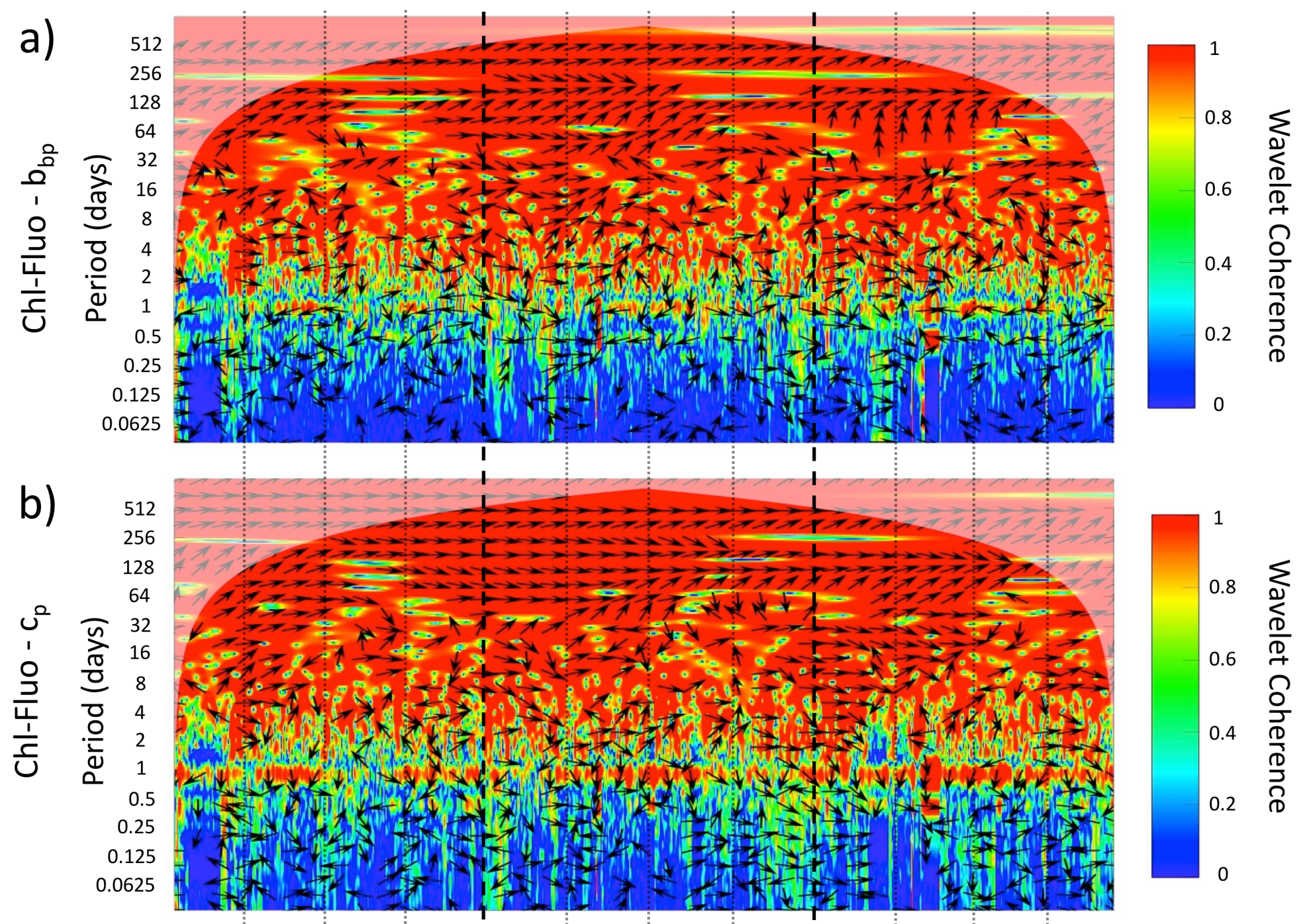

C

C) 512

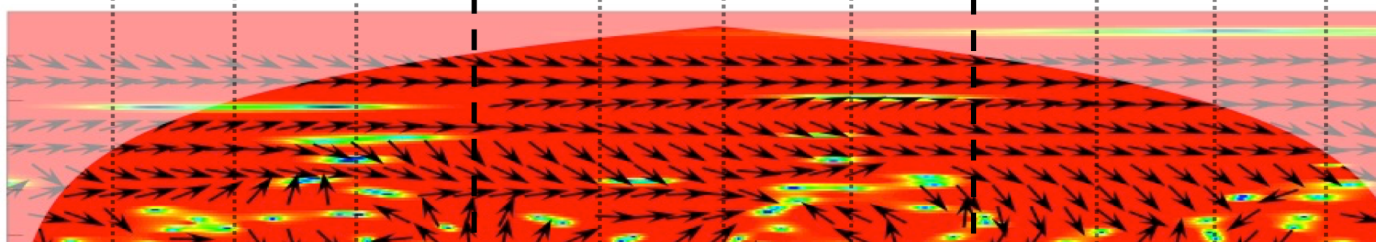

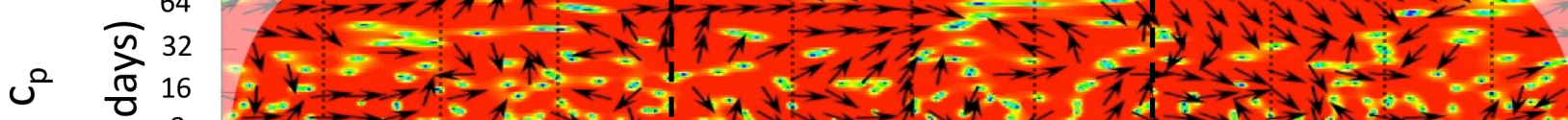

'。

م. 을

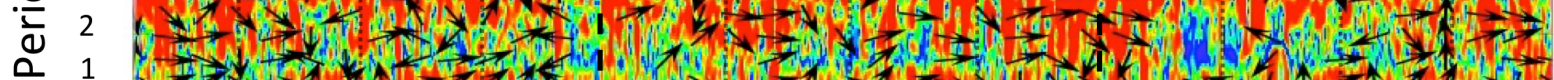

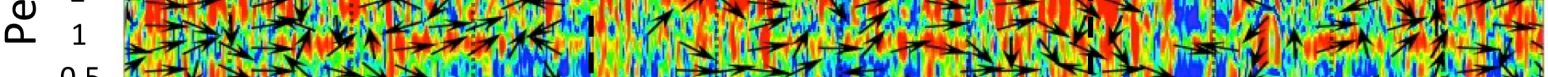

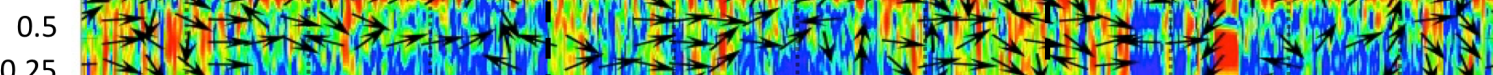

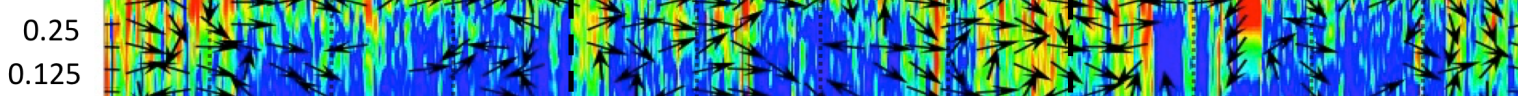

0.0625

NAtr.

7 -

W $\quad$ S $\quad$ S $\quad$ F I W

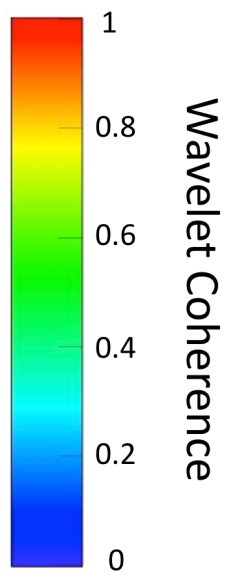


a)

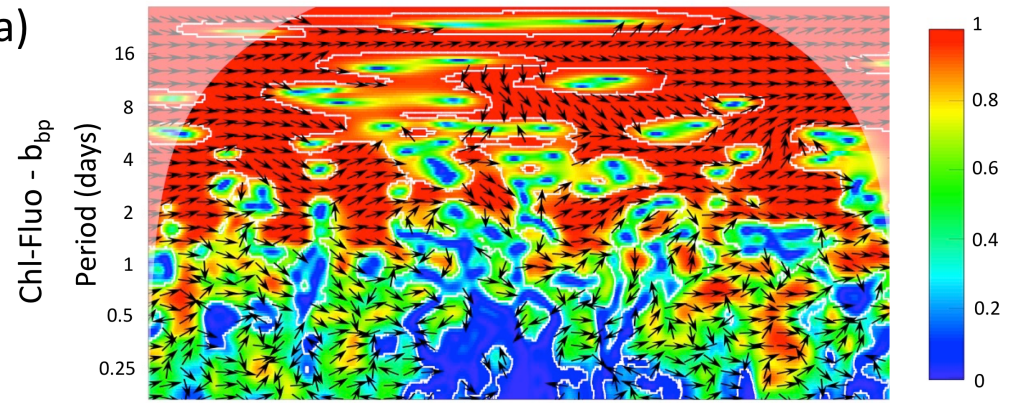

b)

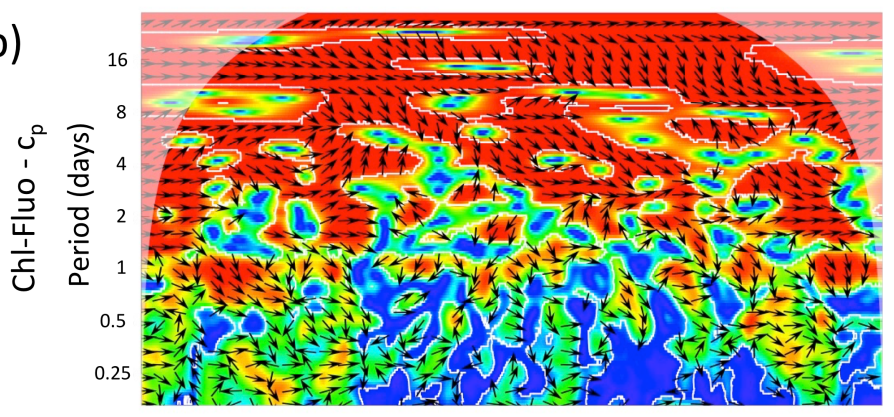

c)

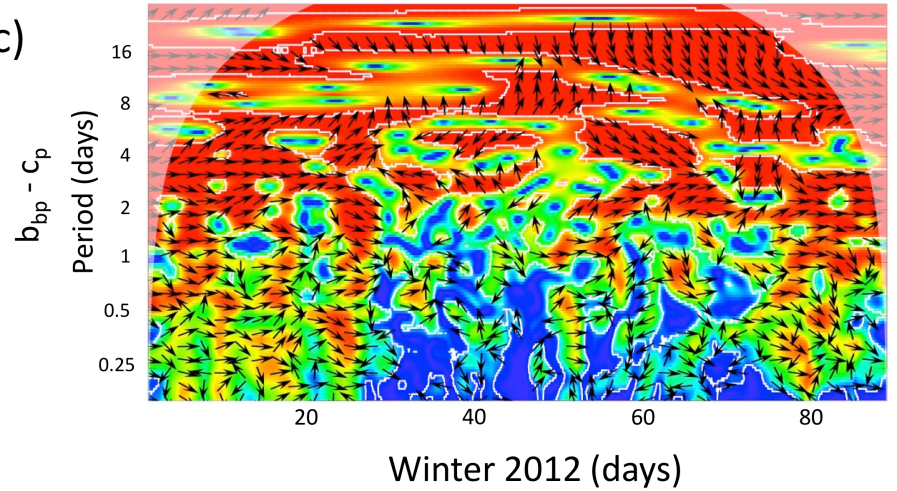

d)

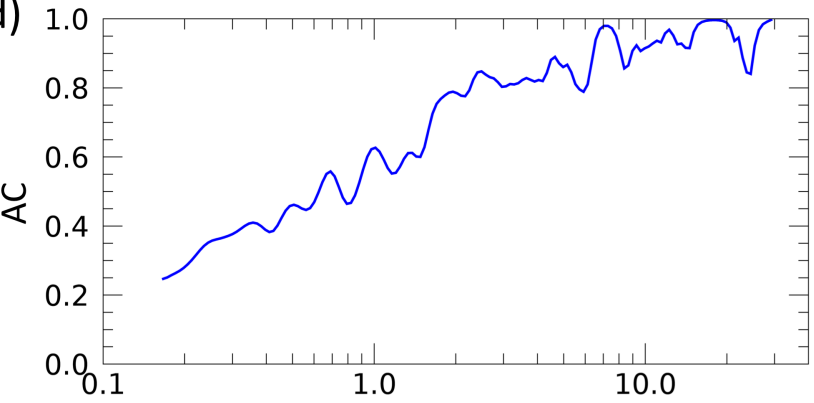

e)
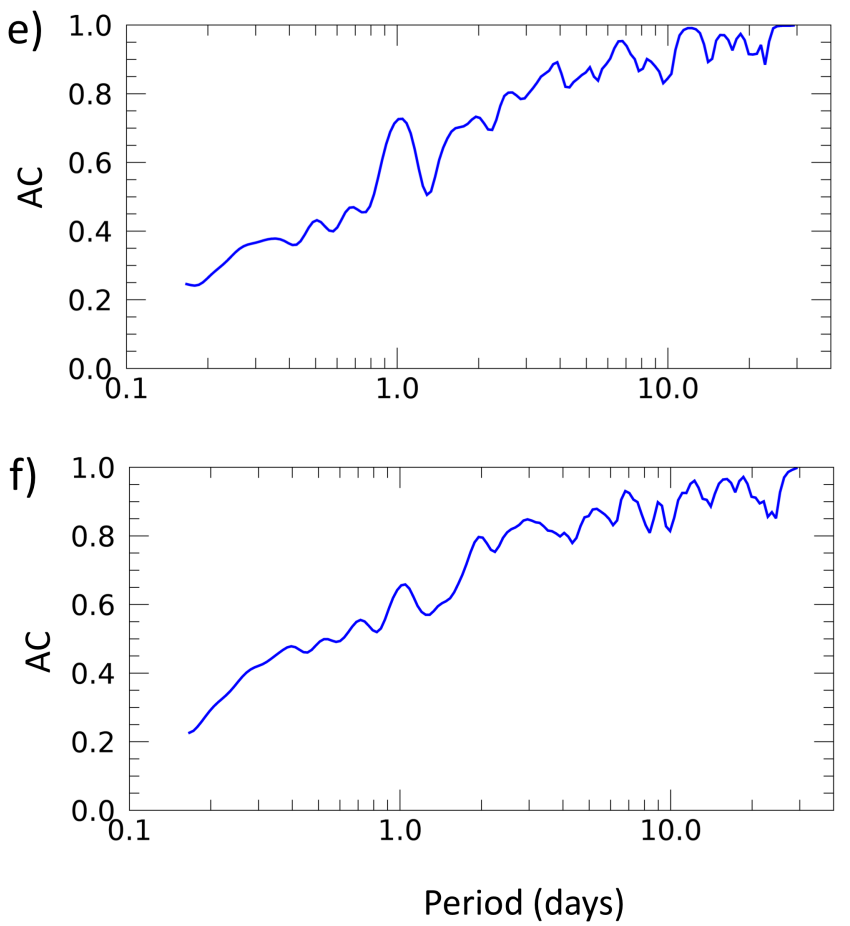
a)

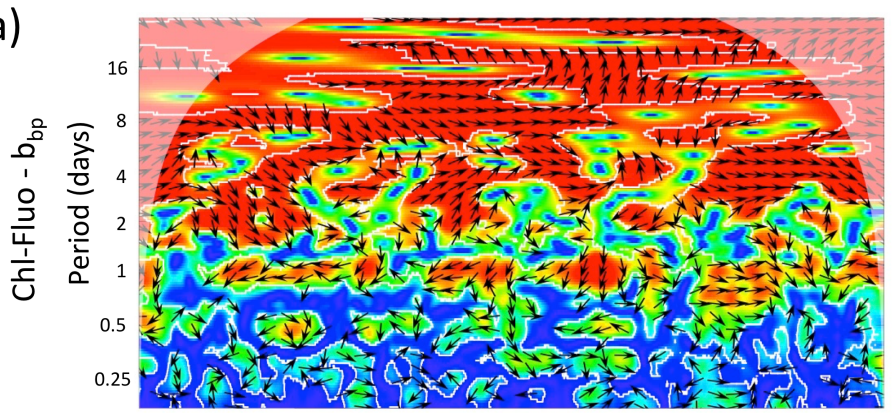

b)

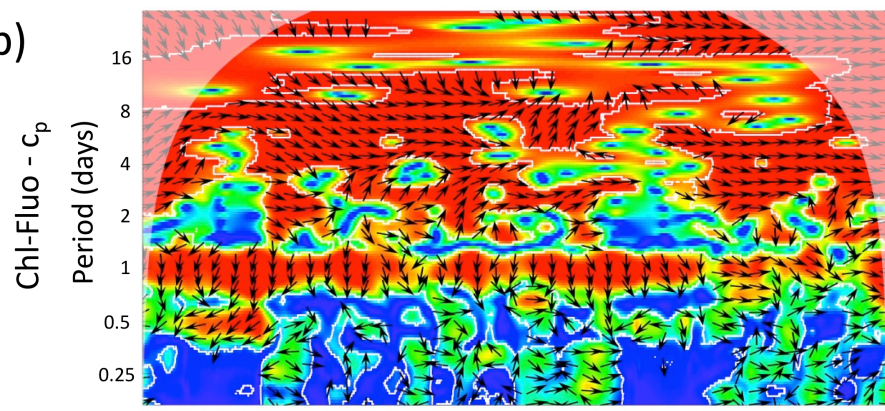

c)

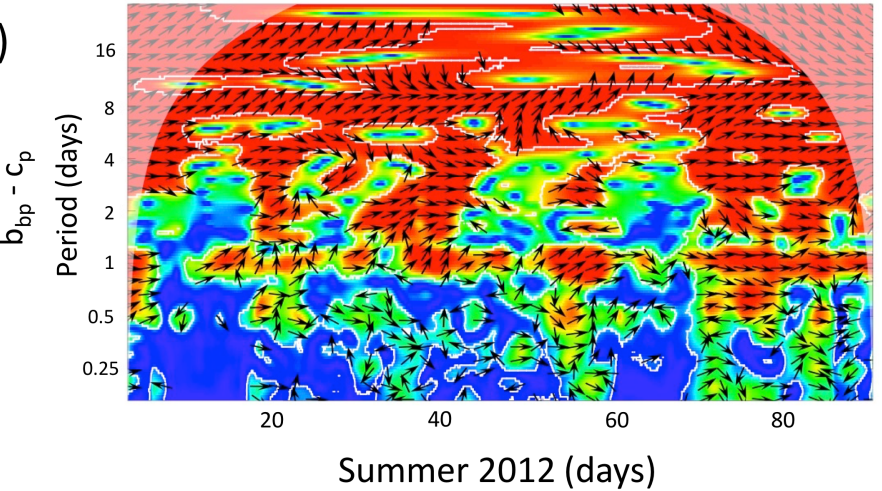

d)
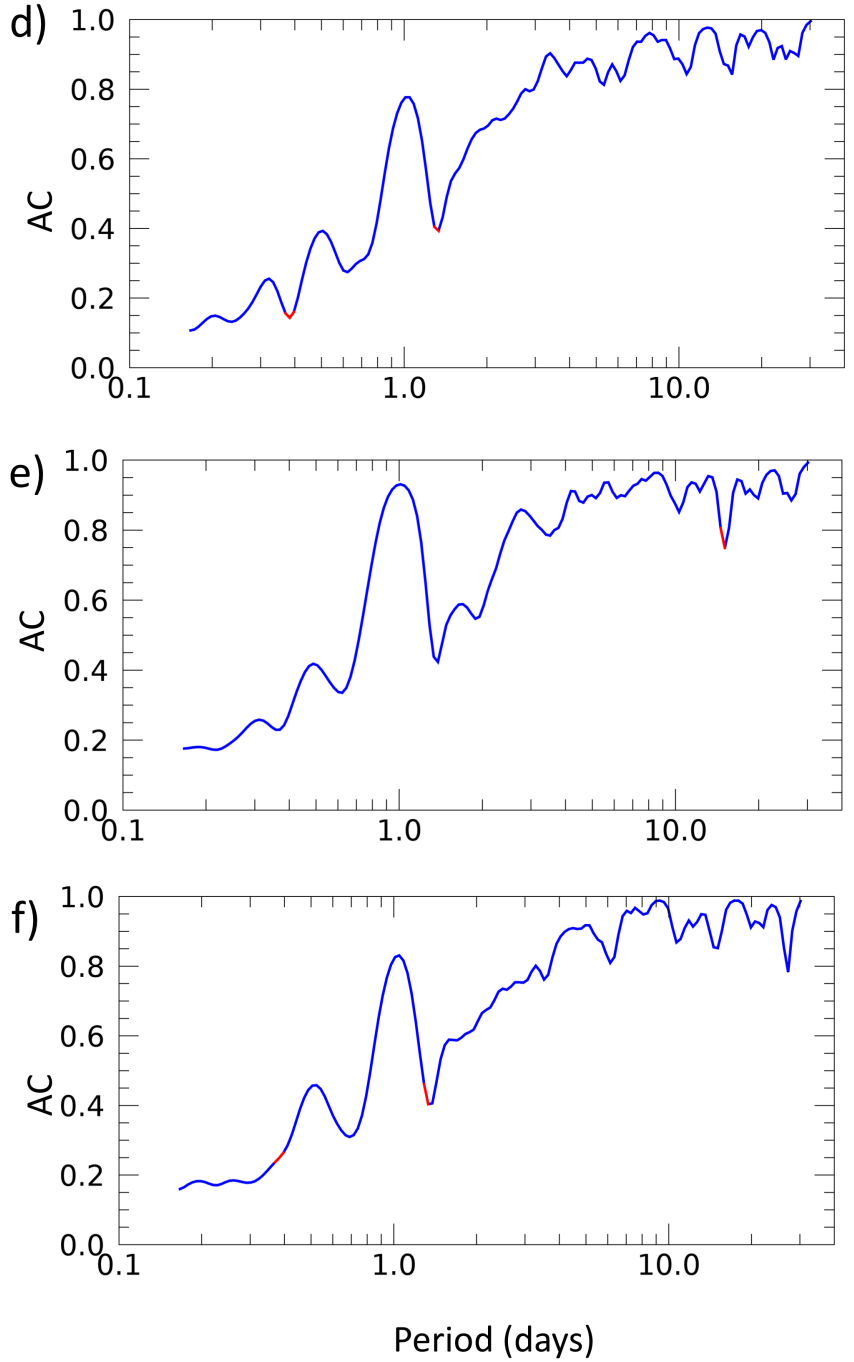